\title{
Acute Kidney Injury in Heart Failure Revisited-The Ameliorating Impact of "Decongestive Diuresis" on Renal Dysfunction in Type 1 Acute Cardiorenal Syndrome: Accelerated Rising Pro B Naturetic Peptide Is a Predictor of Good Renal Prognosis
}

\author{
Macaulay Amechi Chukwukadibia Onuigbo ${ }^{1,2, *}$ (1) , Nneoma Agbasi ${ }^{3}$, Mohan Sengodan ${ }^{4}$ and \\ Karen Flores Rosario ${ }^{4,5}$ \\ College of Medicine, Mayo Clinic, Rochester, MN 55905, USA \\ Department of Nephrology, Mayo Clinic Health System, Eau Claire, WI 54702, USA \\ North East London NHS Foundation Trust, Ilford, Essex 1G3 8XJ, UK; nneomaa@hotmail.com \\ 4 Hospital Medicine, Mayo Clinic Health System, Eau Claire, WI 54702, USA; \\ sengodan.mohan@mayo.edu (M.S.); kpflores@wisc.edu (K.F.R.) \\ 5 Medical School, University of Wisconsin School of Medicine and Public Health, Madison, WI 53726, USA \\ * Correspondence: onuigbo.macaulay@mayo.edu; Tel.: +1-715-838-3891; Fax: +1-715-838-1946
}

Academic Editor: Lindsay Brown

Received: 7 July 2017; Accepted: 23 August 2017; Published: 29 August 2017

\begin{abstract}
There is mounting evidence that forward heart failure as manifested by low cardiac output alone does not define the degree of renal dysfunction in cardiorenal syndrome. As a result, the term "congestive renal failure" was coined in 2012 by Ross to depict the role of renal venous hypertension in type 1 acute cardiorenal syndrome. If so, aggressive decongestive therapies, either through mechanical ultrafiltration with dialysis machines or pharmacologic ultrafiltration with potent diuretics, would lead to improved cardio and renal outcomes. Nevertheless, as recently as 2012, a review of this literature had concluded that a renal venous hypertension-directed approach using diuretics to manage cardio-renal syndrome was yet to be fully investigated. We, in this review, with three consecutive case series, describe our experience with pharmacologic decongestive diuresis in this paradigm of care and argue for studies of such therapeutic interventions in the management of cardiorenal syndrome. Finally, based on our observations in the Renal Unit, Mayo Clinic Health System, in Northwestern Wisconsin, we have hypothesized that patients with cardiorenal syndrome presenting with accelerated rising Pro B Naturetic Peptide levels appear to represent a group that would have good cardio- and renal-outcomes with such decongestive pharmacologic therapies.
\end{abstract}

Keywords: acute decompensated heart failure; cardiorenal syndrome; central venous pressure; congestive heart failure; congestive renal failure; continuous intravenous furosemide infusion; fluid balance; intravenous chlorothiazide; intravenous decongestive diuresis; Pro B Naturetic Peptide; renal venous pressure; renal venous hypertension; serum creatinine; ultrafiltration

\section{Introduction}

Heart Failure, Renal Failure and the Role of Renal Venous Hypertension in Cardiorenal Syndrome: A Review of the Current Literature

There is mounting evidence that forward heart failure as manifested by low cardiac output alone does not define the degree of renal dysfunction in cardiorenal syndrome [1-7]. Consequently, Ross in 2012 referred to kidney dysfunction associated with heart failure as "congestive renal failure" [1]. In an 
analysis of the ADHERE (Acute Decompensated Heart Failure National Registry) database of 118,465 decompensated heart failure admissions, Heywood et al. could not demonstrate an association between left ventricular systolic dysfunction and renal impairment [2]. Moreover, in the ESCAPE (Evaluation Study of Congestive Heart Failure and Pulmonary Artery Catheterization Effectiveness) trial involving hospitalized decompensated heart failure patients, kidney function did not correlate with cardiac index, pulmonary capillary wedge pressure, or systemic vascular resistance, but rather was (weakly) associated with right atrial pressure [3]. Furthermore, Damman et al.'s retrospective analysis of 2557 patients undergoing right heart catheterization demonstrated that elevated central venous pressure (CVP) was associated with low estimated glomerular filtration rate (eGFR) independently from cardiac index, and it predicted mortality [4]. Another set of investigators reported supportive findings in a study of 2647 patients with systolic heart failure, in which depressed eGFR and mortality were associated with congestive findings such as ascites and elevated jugular venous pressure [5]. Likewise, Guglin et al. described catheterization findings in $178 \mathrm{HF}$ patients wherein low eGFR correlated with high CVP and low renal perfusion pressure (mean arterial pressure minus CVP), but not the cardiac index or left ventricular ejection fraction (LVEF) [6]. Similarly, in Maeder et al.'s report of 196 heart failure patients, the echocardiographic severity of tricuspid regurgitation was independently associated with the degree of renal dysfunction [7]. The conclusion was that although a causal relationship cannot be proven, significant tricuspid regurgitation contributes to renal dysfunction in heart failure patients, probably by elevation of central and renal venous pressure [7].

From the foregoing therefore, although experimental, animal and human studies have for more than half a century supported the concept that backward failure with increased renal venous hypertension is a potent etiopathogenetic factor in the causation of renal failure associated with decompensating heart failure, as recently as 2012, a review of this literature had concluded that a renal venous hypertension-directed approach using diuretics to manage cardio-renal syndrome was yet to be fully investigated [1]. This review called for larger and more rigorous trials to definitely establish under what circumstances conventional pharmacologic and ultrafiltration goals might best be directed towards central venous pressures rather than left ventricular or cardiac output parameters [1].

The mission of this manuscript is to describe our experience with three patients presenting to the Renal Unit, Mayo Clinic Health System, Eau Claire, in Northwestern Wisconsin, over three months, May-June 2017, with features of worsening symptomatic congestive heart failure or acute decompensating heart failure with concurrent worsening acute kidney injury (cardiorenal syndrome) and the response of these patients to conventional pharmacologic diuresis, leading to improvement in both heart failure symptoms and acute kidney injury. Following that is a discussion of the utility and pharmacodynamics of combination intravenous Thiazide-Loop diuretics in this paradigm of care. Such therapeutic maneuvers would prove invaluable to practitioners in resource-poor settings without access to mechanical ultrafiltration with dialysis or similar equipment.

\section{Case Reports}

\subsection{Case 1}

In early March 2017, the Nephrology service was consulted to see an overweight 83-year-old female patient admitted to the Hospitalist service a week earlier with dyspnea and volume overload from symptomatic heart failure complicated by rapid ventricular response atrial fibrillation, against a background history of hypertension and stage 3 CKD. Other pertinent past medical history include hypertension, sarcoidosis, COPD, atrial fibrillation and type 2 diabetes mellitus. A month earlier, she was discharged after 5 days with symptomatic hypotension and dizziness associated acute kidney injury with peak creatinine of $2.21 \mathrm{mg} / \mathrm{dL}$, and then associated with UTI that was treated with Bactrim. At the time she was also on Lisinopril, which was then discontinued. Subsequently following conservative management in the hospital, kidney function as measured by the serum creatinine had returned to near baseline of $0.96 \mathrm{mg} / \mathrm{dL}$ at discharge. 
This time in March 2017, she had become increasingly short of breath and hypotensive as well and serum creatinine had risen back up again to as high as $1.79 \mathrm{mg} / \mathrm{dL}$ at the time of the Nephrology consultation. Temperature was $36.9^{\circ} \mathrm{C}$, heart rate $67 \mathrm{per} / \mathrm{min}$, respiratory rate $18 \mathrm{per} / \mathrm{min}$, oxygen saturation $90 \%$ on room air, and blood pressure was 106/60. She weighed up to $75.4 \mathrm{~kg}$, height was $163 \mathrm{~cm}$, with a BMI of $28.4 \mathrm{~kg} / \mathrm{m}^{2}$. She was dyspneic, JVD was elevated, with $2+$ bilateral extremity edema and reduced breath sounds in both lung bases bilaterally, with bibasilar inspiratory rales evident posteriorly. Admission chest radiograph showed cardiomegaly, new bilateral pleural effusions, pulmonary vascular congestion and hypoventilation. Echocardiogram revealed normal left ventricular systolic function with ejection fraction of $64 \%$, mild mitral valve regurgitation, bi-atrial enlargement, normal right ventricular function with right ventricular systolic pressure of $29 \mathrm{mmHg}$. At the time of this consultation, serum albumin was $2.8 \mathrm{~g} / \mathrm{dL}$, sodium was $134 \mathrm{mmol} / \mathrm{L}$, potassium 3.6 $\mathrm{mmol} / \mathrm{L}$, chloride $94 \mathrm{mmol} / \mathrm{L}$, bicarbonate $24 \mathrm{mmol} / \mathrm{L}$, calcium $8.9 \mathrm{~g} / \mathrm{dL}$, hematocrit $24.9 \%$, WBC, platelets, TSH, Free T4, AST, ALT and total bilirubin were all normal. Pro Pro B Naturetic Peptide level that was elevated at $581 \mathrm{pg} / \mathrm{mL}$ on 2 February 2017 had rapidly escalated to $4907 \mathrm{pg} / \mathrm{mL}$ by 23 February 2017, three weeks later, just prior to this admission (Pro Pro B Naturetic Peptide reference range $\leq 450 \mathrm{pg} / \mathrm{mL}$ ).

Earlier in the admission, she was started on intravenous amiodarone for rate control of atrial fibrillation. Furthermore, oral Diltiazem, $120 \mathrm{mg}$ three times a day, was subsequently discontinued when she became hypotensive. She had been started on continuous intravenous Furosemide infusion at $10 \mathrm{mg} / \mathrm{h}$ but the previous $24-\mathrm{h}$ urine output was only $1500 \mathrm{cc}$.

We doubled the dose of intravenous continuous infusion of Furosemide to $20 \mathrm{mg} / \mathrm{h}$ and added intravenous Chlorothiazide $500 \mathrm{mg}$ every $12 \mathrm{~h}$. The chlorothiazide was discontinued after one dose when the patient raised concerns for a history of drug-induced pancreatitis. We then increased the dose of intravenous Furosemide to $25 \mathrm{mg} / \mathrm{h}$, added daily intravenous Albumin $25 \mathrm{gm}$ infusion to run concurrently with the continuous Furosemide infusion because of severe hypoalbuminemia. The edematous legs and feet were elevated and wrapped with ACE wraps. Overnight, urine output had more than doubled to $3450 \mathrm{cc}$ (Figure 1). Subsequently, twenty-four urine output increased to over 3-4 L (Figure 1). After 5 days of the Furosemide infusion, she was switched to oral Bumetanide $2 \mathrm{mg}$ twice daily. She continued to make urine in excess of $2.5 \mathrm{~L}$ an day and was discharged after another two days, much improved with edema, dyspnea and orthopnea resolved, together with significant weight loss (Figure 2). She had achieved a weight loss of $12 \mathrm{~kg}$ during the last nine days of the admission. Her serum creatinine trajectory also improved during the second half of this admission and serum creatinine at discharge was $1.29 \mathrm{mg} / \mathrm{dL}$ (Figures 3 and 4).

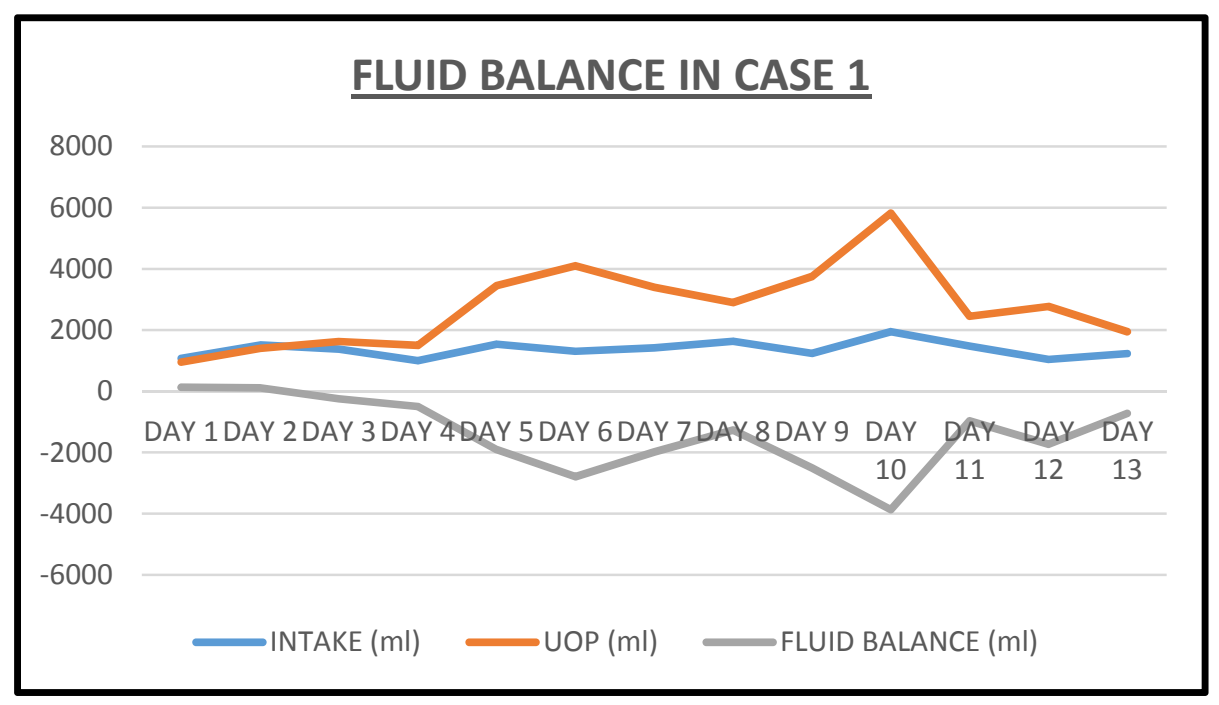

Figure 1. Fluid balance with total intake and urine output in Case 1 during the index admission. 


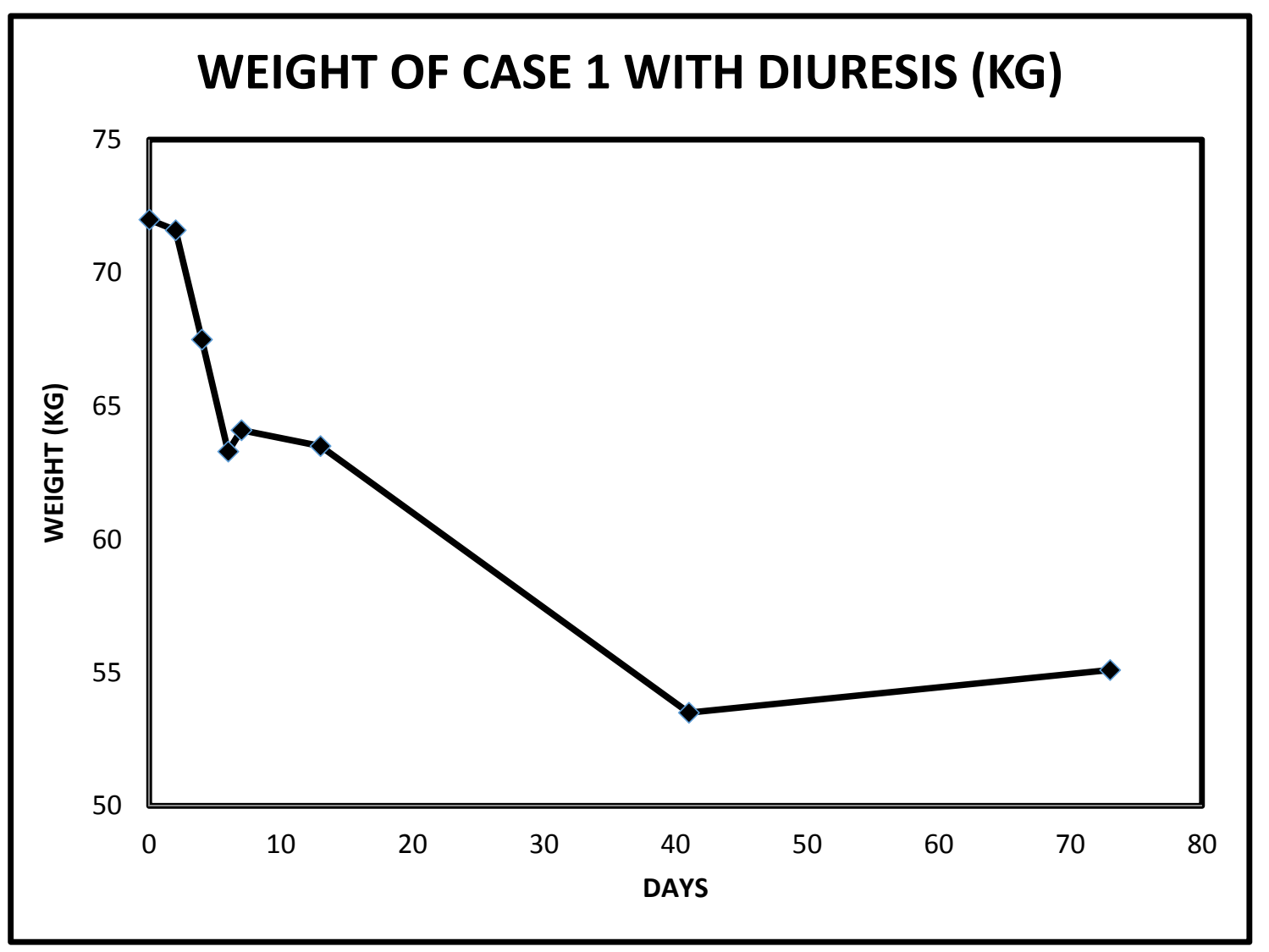

Figure 2. Weight changes following intravenous decongestive diuresis in Case 1.

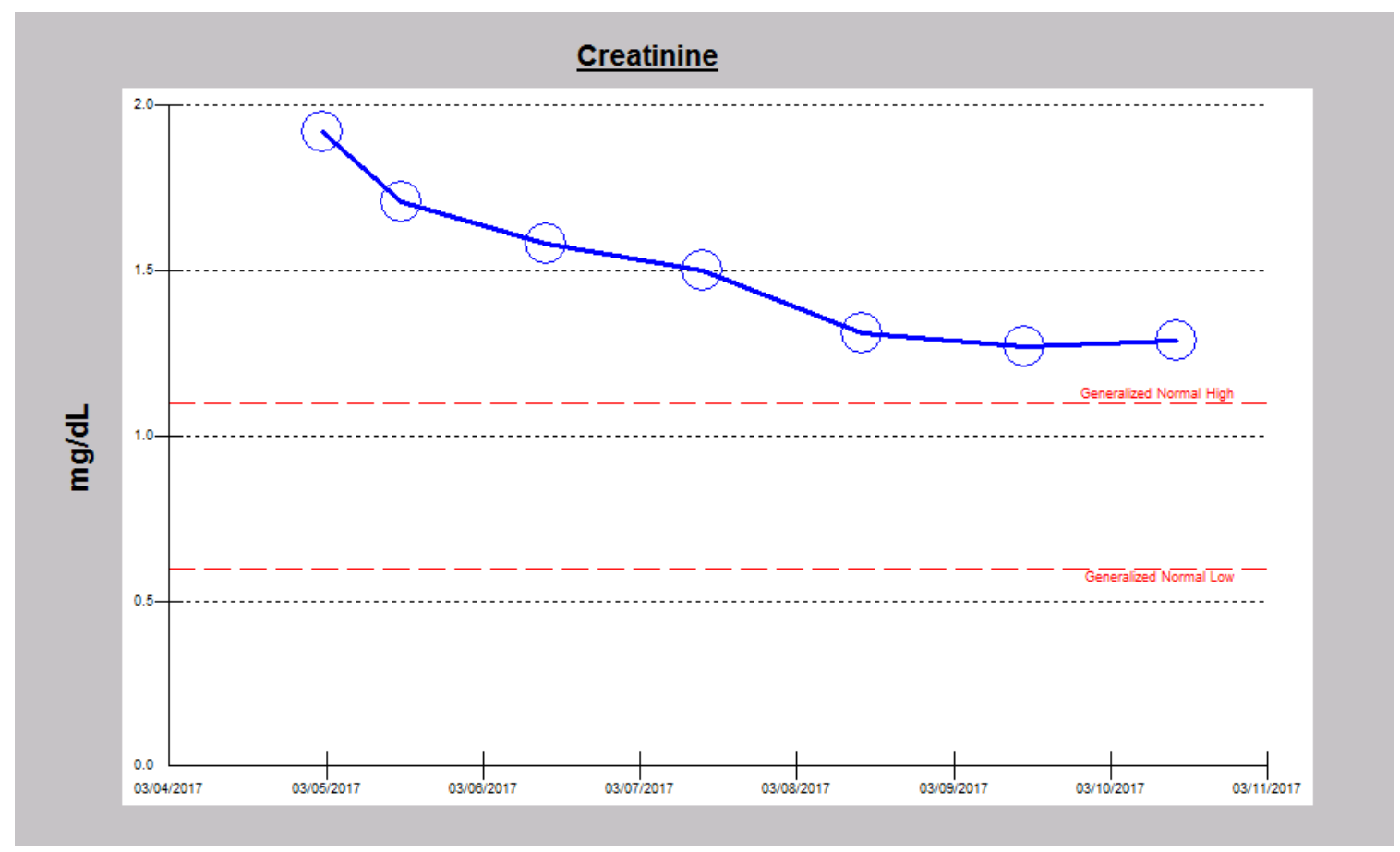

Figure 3. Falling serum creatinine in Case 1 following intravenous decongestive diuresis, 4-11 March 2017. 


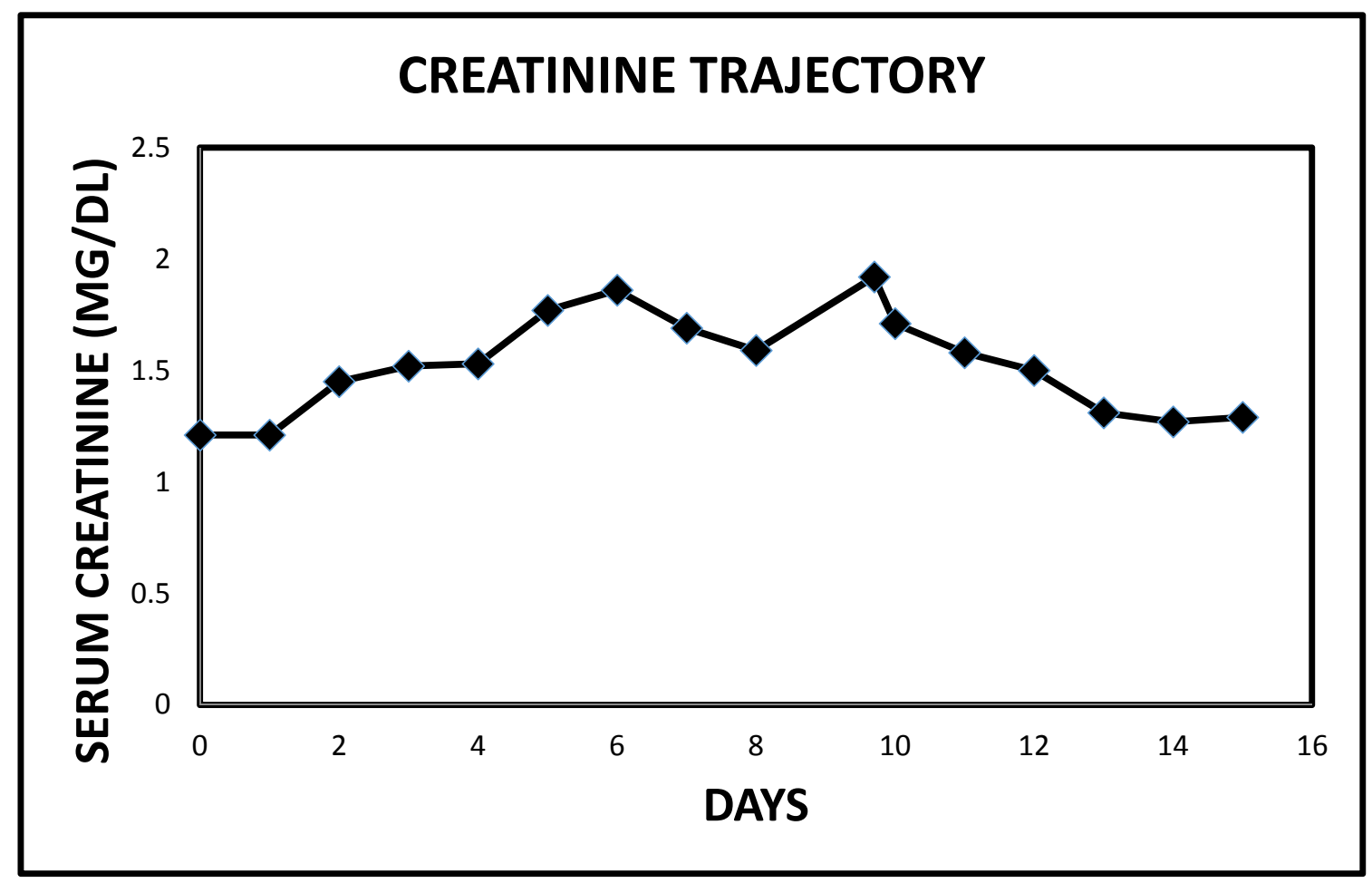

Figure 4. Serum creatinine trajectory in Case 1 leading to and following the use of intravenous decongestive diuresis, 4-11 March 2017.

\subsection{Case 2}

In mid-May 2017, an 84-year old Caucasian male was readmitted to our hospital, after two months, from a Nursing Home with worsening shortness of breath, orthopnea, and inability to get around his assisted living facility despite the use of $24 / 7$ nasal cannula oxygen at $2 \mathrm{~L} / \mathrm{min}$. Past medical history was significant for severe oxygen-dependent COPD in an ex-smoker, chronic diastolic heart failure, obstructive sleep apnea, type II diabetes mellitus, atrial fibrillation, hypertension, tricuspid regurgitation, cor pulmonale with worsening pulmonary hypertension, previous coronary artery bypass and chronic kidney disease stage IIIB with serum creatinine of $1.93 \mathrm{mg} / \mathrm{dL}$ (eGFR $=33 \mathrm{~mL} / \mathrm{min} / 1.73$ sq. $\mathrm{m} \mathrm{BSA}$ in late March 2017). Outpatient medications included Metoprolol $25 \mathrm{mg}$ twice daily, insulin and Torsemide $10 \mathrm{mg}$ twice daily. In the Emergency Department, his oxygen saturation was $87 \%$ on $2 \mathrm{~L}$ per minute nasal cannula oxygen. Temperature was $36.4{ }^{\circ} \mathrm{C}$, pulse was $76 / \mathrm{min}$, respiratory rate $22 / \mathrm{min}$ and $\mathrm{BP}$ was $120 / 87$. His oxygen saturation improved to $97 \%$ on high flow oxygen. He weighed $75 \mathrm{~kg}$, height was $193 \mathrm{~cm}$, with a BMI of $20.1 \mathrm{~kg} / \mathrm{m}^{2}$. Jugular venous distension was present and he had bilateral pitting pretibial edema. The lungs revealed bilateral basal inspiratory crepitations. Hemoglobin was $13.3 \mathrm{~g} / \mathrm{dL}$, Pro B Naturetic Peptide level was grossly elevated at 38,547 pg/mL (<450), from a level of 16,711 pg/mL in January 2017 (Pro B Naturetic Peptide reference range $\leq 450 \mathrm{pg} / \mathrm{mL}$ ). Simultaneously, the serum creatinine had increased from a baseline of $1.65 \mathrm{mg} / \mathrm{dL}$ in January 2017 to $3.09 \mathrm{mg} / \mathrm{dL}$ (Figure 5). Other pertinent laboratory indices were chloride $91 \mathrm{mmol} / \mathrm{L}$, bicarbonate $31 \mathrm{mmol} / \mathrm{L}$ but with otherwise normal other electrolytes. Chest radiograph revealed cardiomegaly, hypoventilation, bibasilar atelectasis and pulmonary vascular congestion. On echocardiogram, the left ventricular function was preserved at 55-60\% but the right ventricular systolic pressure had risen from $64 \mathrm{~mm} \mathrm{Hg}$ in December 2016 to $72 \mathrm{~mm} \mathrm{Hg}$ in mid-May 2017, together with severe right atrial enlargement. 


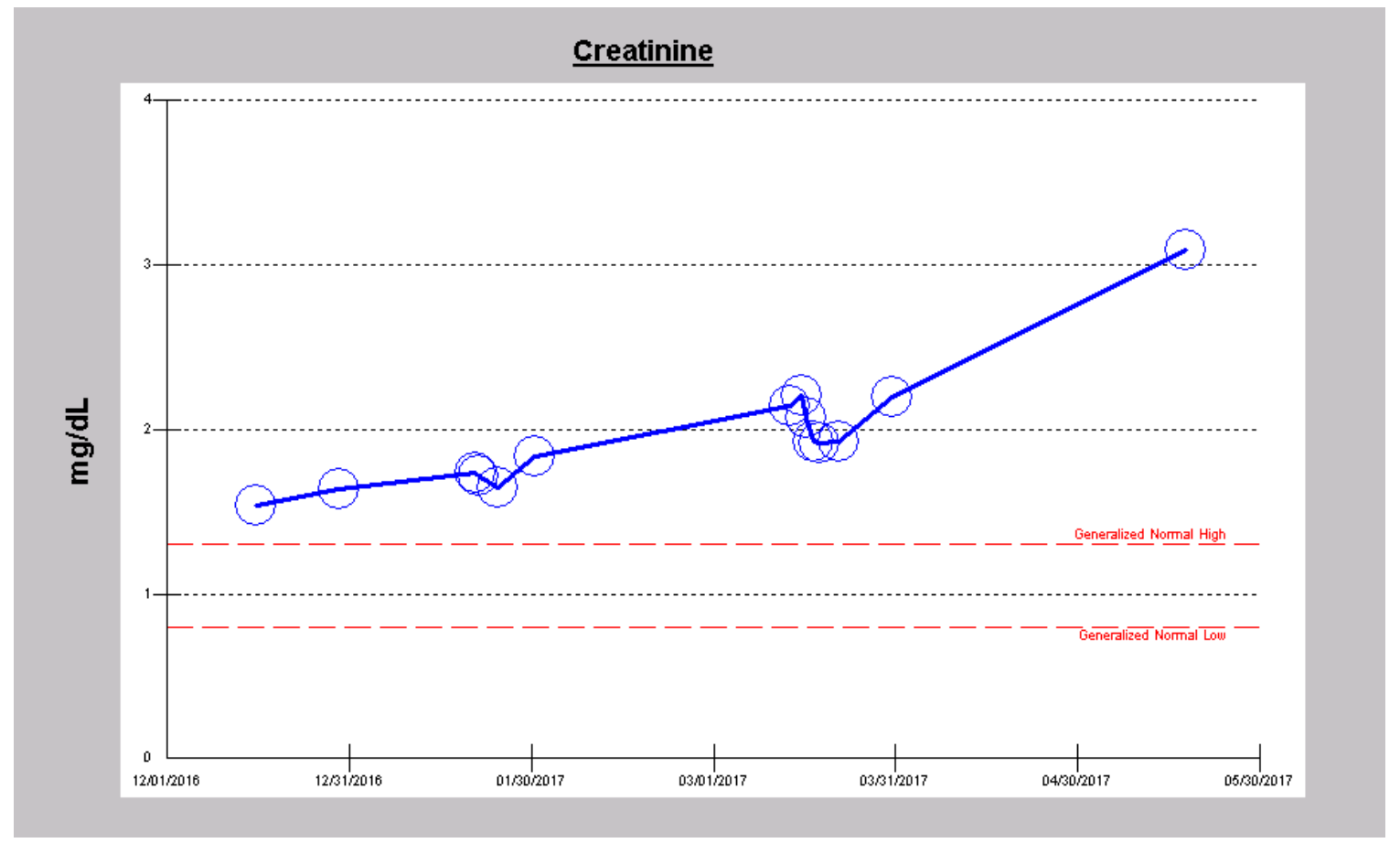

Figure 5. Worsening serum creatinine trajectory in Case 2 leading to the admission in mid-May 2017.

He was started on continuous infusion Furosemide at $20 \mathrm{mg} / \mathrm{h}$, together with concurrent intravenous Chlorothiazide $500 \mathrm{mg}$ every $8 \mathrm{~h}$. Overnight, in just over $12 \mathrm{~h}$, he had made $1.8 \mathrm{~L}$ of urine with only $207 \mathrm{cc}$ as intake. Over the next two days, diuresis continued with increasing urine output (Figure 6) and decreasing weight (Figure 7). He continued to improve and by the third admission day, both intravenous diuretics were discontinued. Leg edema had resolved, dyspnea had stabilized and serum creatinine had continued to improve (Figure 8).

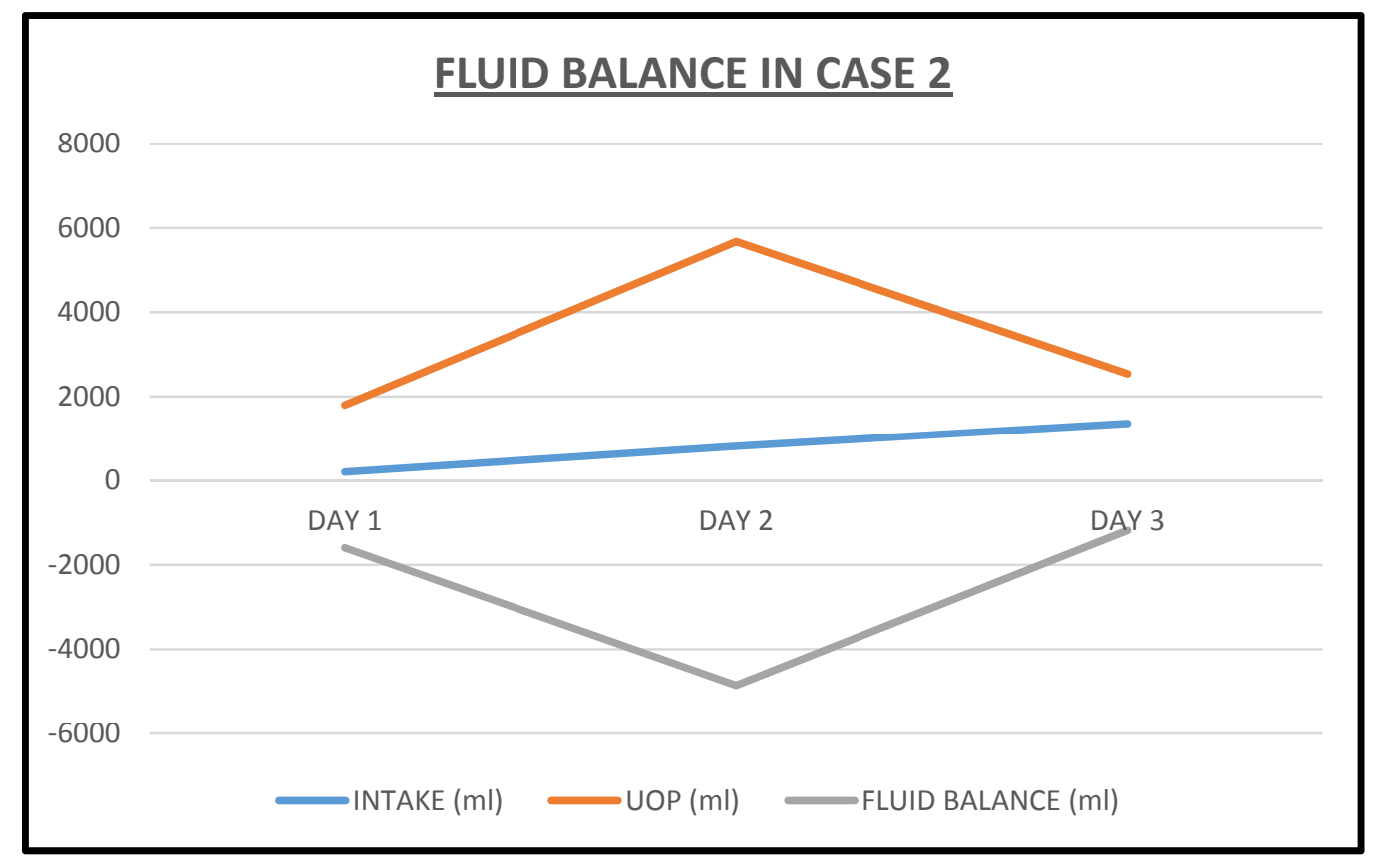

Figure 6. Fluid balance with total intake and urine output in Case 2 during the index admission. 


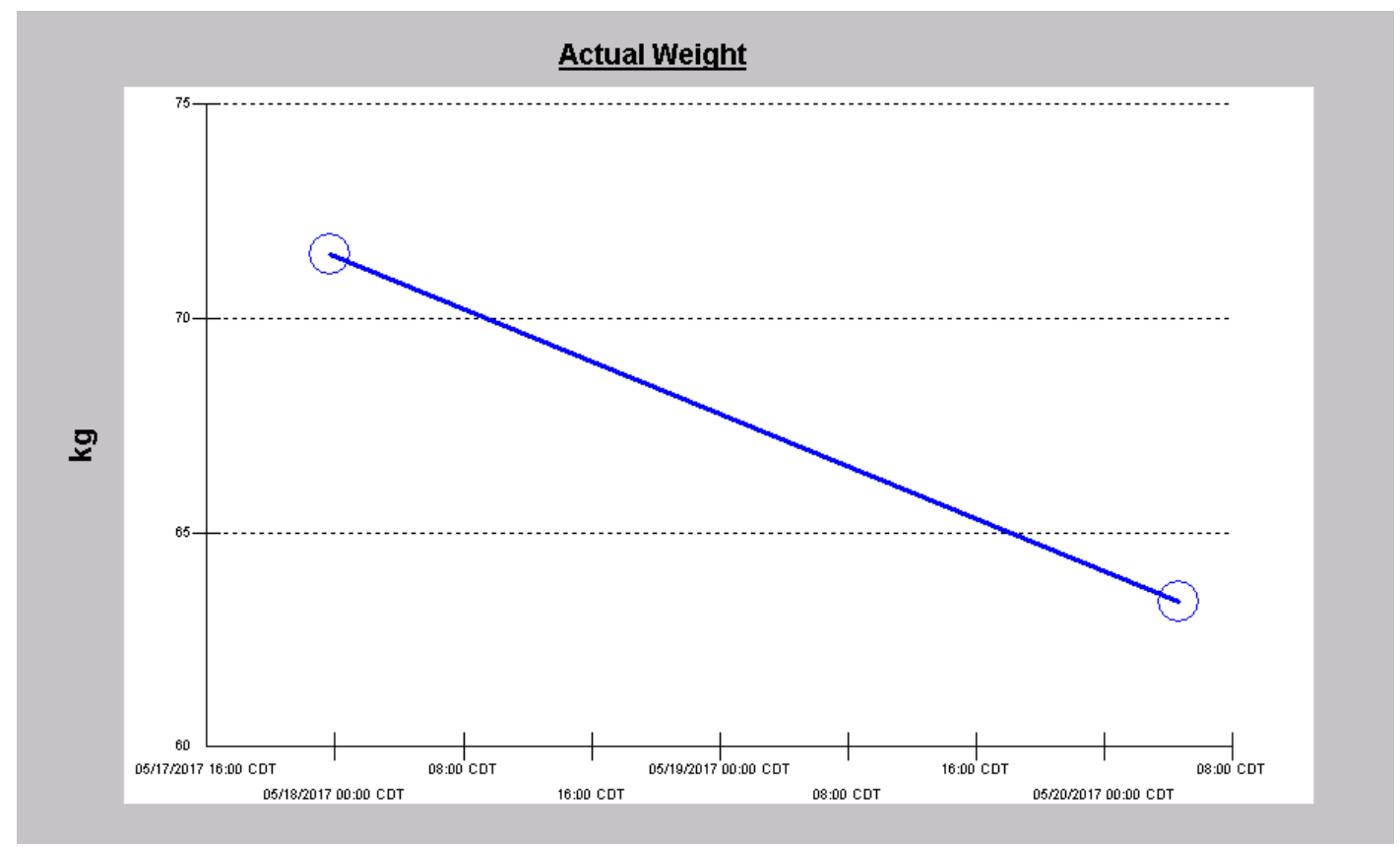

Figure 7. Weight reduction following intravenous decongestive diuresis in Case 2.

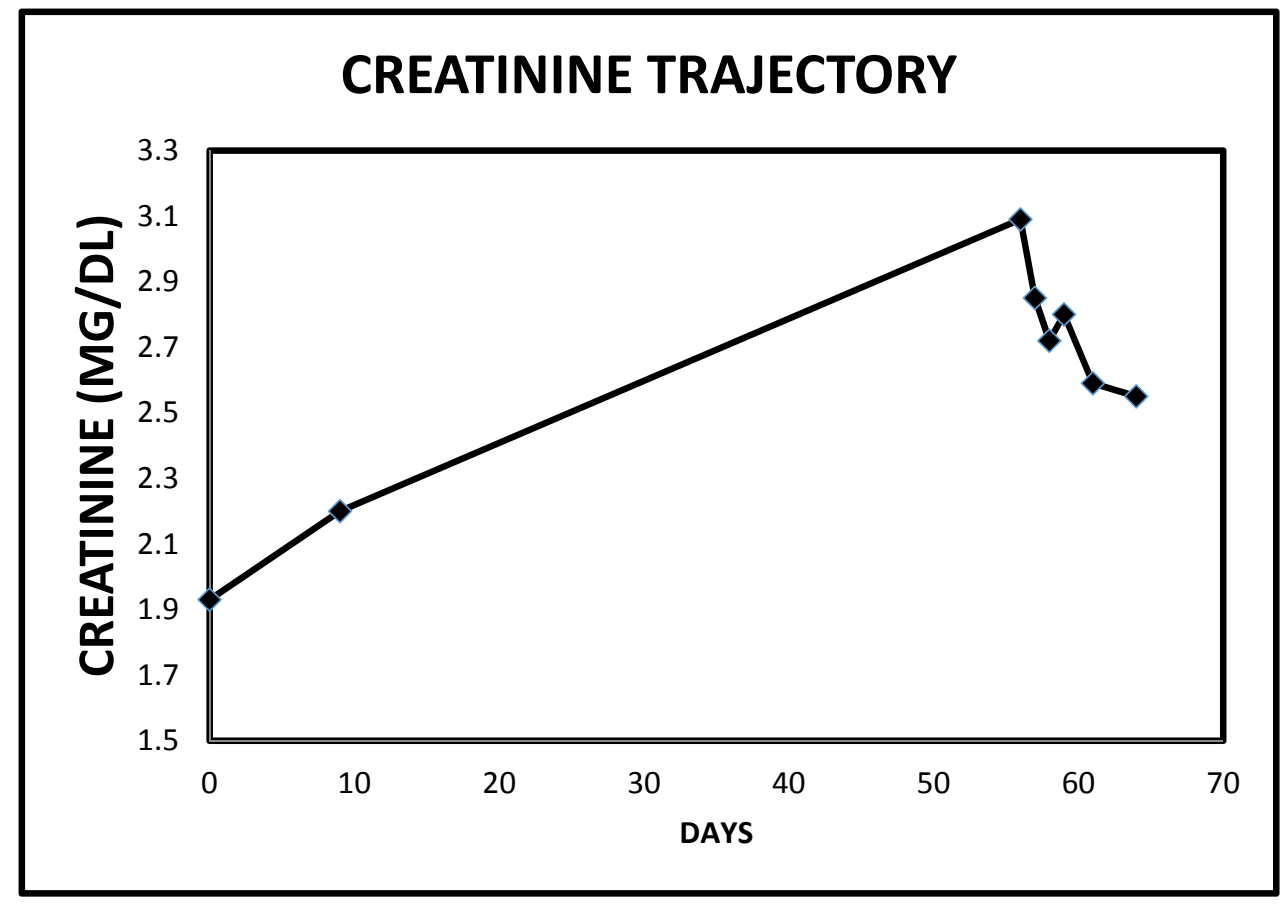

Figure 8. Serum creatinine trajectory in Case 2 following the use of intravenous decongestive diuresis.

He was switched to oral Torsemide, $20 \mathrm{mg}$ twice daily, together with oral Metolazone, $2.5 \mathrm{mg}$ every other day, as an adjunct diuretic agent. Foley catheter was removed and he was discharged much improved to the Nursing Home. Nevertheless, two days after his discharge to the Nursing Home, he became increasingly weak, despite improved dyspnea and still improving kidney function. The patient at this point, with the support of the family, in view of all the concurrent comorbidities, opted for hospice care and he peacefully passed away about a week afterwards. 


\subsection{Case 3}

A morbidly obese 62-year old Caucasian male patient was transferred from a Nursing Home in June 2017 by ambulance with worsening dyspnea, oxygen desaturation of about $70 \%$ and hypotension to our Emergency Department. Past medical history was significant for morbid obesity, likely sleep apnea, chronic hypercapnic respiratory failure from COPD, peripheral vascular disease, venous insufficiency, generalized debility, preserved left ventricular ejection fraction of $72 \%$, and hypertension with early stage II CKD, with baseline serum creatinine of less than $1 \mathrm{mg} / \mathrm{dL}$. Pertinent outpatient medications included potassium chloride $40 \mathrm{mEq}$ twice daily, spironolactone $25 \mathrm{mg}$ daily which was started two days before this admission, Furosemide $20 \mathrm{mg}$ twice daily, Duonebs, baby Aspirin, Gabapentin $600 \mathrm{mg}$ twice daily, Oxycodone $10 \mathrm{mg}$ extended release twice daily, pantoprazole and Atorvastatin. The patient had undergone an aortogram with run off followed by a left lower extremity angioplasty for a high-grade proximal left femoral-popliteal bypass in situ vein stenosis two days prior to the admission - he had required temporary intubation for this procedure that was otherwise successful and without other complications.

Initial blood pressure was $88 / 63$, pulse $71 / \mathrm{min}$ and oxygen saturation quickly improved to $99 \%$ on BIPAP. He weighed $133.5 \mathrm{~kg}$, height was $190 \mathrm{~cm}$, with a BMI of $36.84 \mathrm{~kg} / \mathrm{m}^{2}$. He had 2+ bilateral lower extremity edema, and chest examination revealed reduced breath sounds with bibasilar inspiratory rales heard posteriorly. Serum creatinine was $3.14 \mathrm{mg} / \mathrm{dL}$, a significant increase from a week previously (Figure 9). Other pertinent laboratory indices were serum potassium $7 \mathrm{mmol} / \mathrm{L}$, serum bicarbonate $27 \mathrm{mmol} / \mathrm{L}$, phosphorus $7.1 \mathrm{mg} / \mathrm{dL}$ with a normal anion gap of $13 \mathrm{mmol} / \mathrm{L}$. He was in respiratory acidosis and respiratory failure with arterial blood gas $\mathrm{pH}$ of $7.18, \mathrm{pCO}_{2}$ of $84 \mathrm{~mm} \mathrm{Hg}$, and bicarbonate of $30 \mathrm{mmol} / \mathrm{L}$. His Pro B Naturetic Peptide level that was nearly normal in August 2016 at $151 \mathrm{pg} / \mathrm{mL}$ was grossly elevated at $1426 \mathrm{pg} / \mathrm{mL}$ in mid May 2017, and had further escalated to $5503 \mathrm{pg} / \mathrm{mL}$ on the day of admission in June 2017 (Pro B Naturetic Peptide reference range $\leq 125 \mathrm{pg} / \mathrm{mL}$ ). There was in addition, mild rhabdomyolysis with total CK of $1720 \mathrm{U} / \mathrm{L}$, ALT was normal at $17 \mathrm{U} / \mathrm{L}$ but AST was mildly elevated at $54 \mathrm{U} / \mathrm{L}$. Lactic acid was normal. EKG was abnormal but the first degree AV block, possible inferior infarct and prolonged QT interval were not new and $\mathrm{T}$ waves were not prominent. Chest radiograph revealed worsening cardiomegaly when compared to October 2016, hypoventilation, pulmonary vascular congestion and basal atelectatic changes without overt infiltrates evident. Echocardiogram was not available. He received two $500 \mathrm{cc}$ boluses of normal saline and his blood pressure stabilized with SBP $>120 \mathrm{~mm} \mathrm{Hg}$. Other emergent therapies for the hyperkalemia included Ipratropium-Albuterol nebulizer treatments, two ampoules of intravenous Dextrose 50 (25 gm each) infusions, intravenous regular insulin and oral Kayexalate, $15 \mathrm{gm}$ in $60 \mathrm{~mL}$ given once [8].

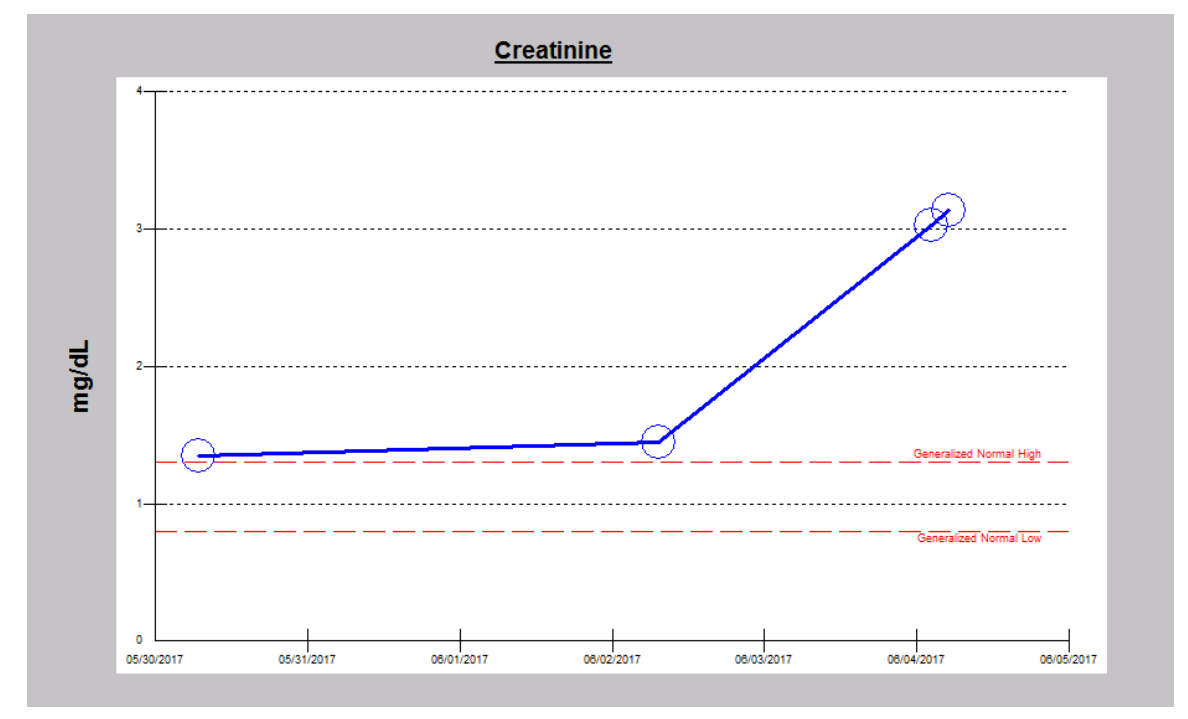

Figure 9. Worsening serum creatinine trajectory in Case 3 leading to the admission in early June 2017. 
Nephrology service was consulted. Evaluation confirmed gross $2+$ to $3+$ bilateral lower extremity edema, ascites, anasarca with reduced breath sounds with bibasilar inspiratory rales heard posteriorly. A Foley catheter was inserted due to evidence of urinary retention. The working diagnosis was contrast-induced nephropathy, further complicated by severe dyspnea likely the combination of chronic obstructive pulmonary exacerbation, narcotic/Gabapentin toxicity, with volume overload and diastolic congestive heart failure, given an otherwise normal echocardiogram in August 2016 with left ventricular ejection fraction of $72 \%$. Spironolactone, Oxycodone, Gabapentin and potassium chloride were promptly discontinued. Continuous intravenous Furosemide infusion was started at $20 \mathrm{mg} / \mathrm{h}$ together with concurrently administered intravenous Chlorothiazide $500 \mathrm{mg}$ every $8 \mathrm{~h}$, and serum creatinine and electrolytes were monitored every $6 \mathrm{~h}$. In addition, oral Doxycycline for longstanding cough and discolored sputum production, together with oral Prednisone and inhaled steroids were added later during the admission. He also went back on the BiPaP machine, which had been discontinued by the patient some months earlier for unclear reasons.

Overnight, the patient exhibited a very prompt, excellent and sustained diuresis with the combination diuretic regimen as he made nearly $10 \mathrm{~L}$ of urine the first admission day (Figure 10). He felt much better, was off the BiPaP during the day, was less dyspneic and leg swelling was significantly reduced bilaterally. His weight quickly dropped, and the serum potassium was normalized about $15 \mathrm{~h}$ into the admission and continued to decrease thereafter (Figures 11 and 12). Simultaneously, serum bicarbonate had risen sharply, a reflection of contraction alkalosis. Moreover, hyperphosphatemia improved concurrently with acutely falling serum creatinine values (Figures 13 and 14).

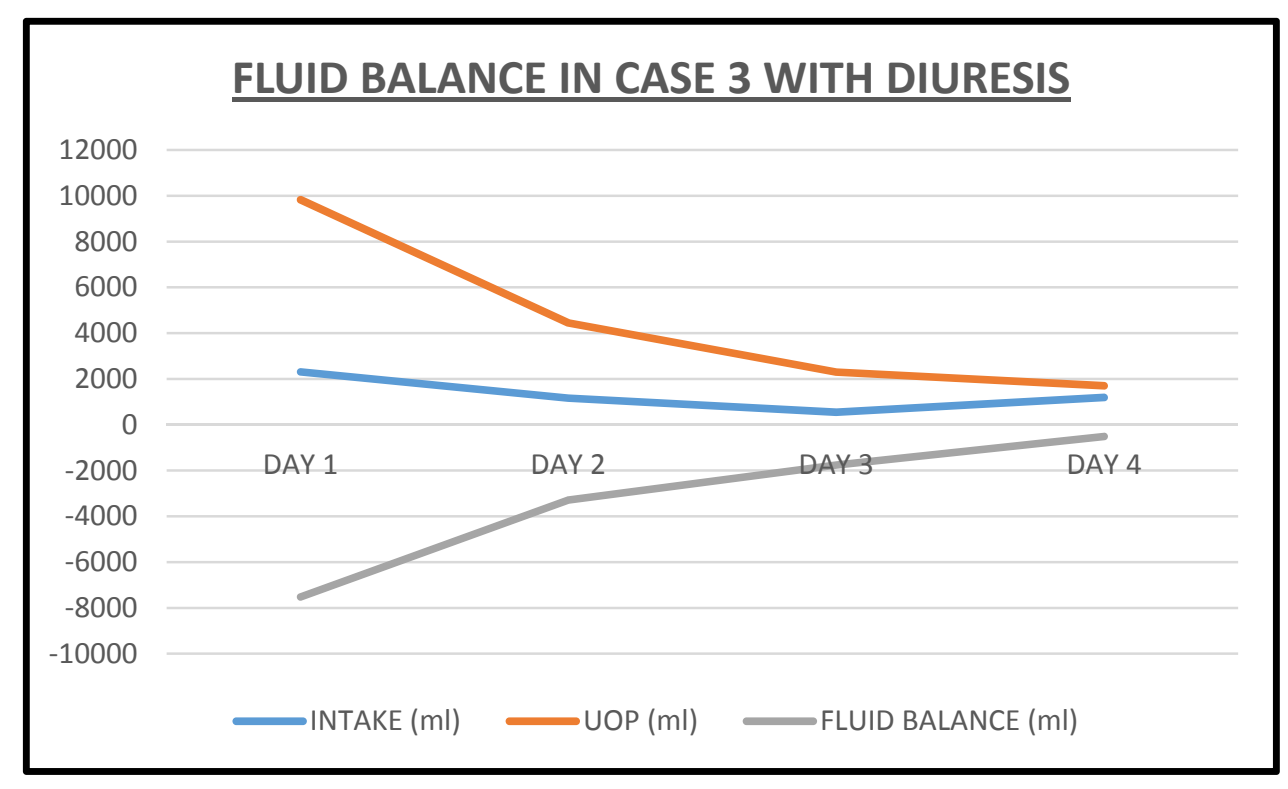

Figure 10. Fluid balance with total intake and urine output in Case 3 during the index admission.

By day 3 , he was feeling so much better that intravenous diuretics were discontinued and he was switched to oral Furosemide $40 \mathrm{mg} 2$ times a day together with oral Metolazone $2.5 \mathrm{mg}$ daily with continued monitoring of intake/output and daily chemistry. The Foley catheter was also discontinued. He continued to improve, lost more weight with loss of anasarca and edema fluids and was discharged after 5 days on the combination oral Furosemide $40 \mathrm{mg}$ twice daily (double the preadmission dose) and oral Metolazone $2.5 \mathrm{mg}$ daily (a new additional diuretic). At discharge, four days later, serum creatinine had fallen to $1.32 \mathrm{mg} / \mathrm{dL}$, phosphorus was normal and he needed potassium supplements for hypokalemia. Besides, the serum bicarbonate was beginning to trend towards normal levels again (Figure 15). Discharge medications included Prednisone taper and he was to complete five days of oral Doxycycline. Lisinopril and Spironolactone remained discontinued at the time of the discharge. He was seen the following week at follow up, in the Nephrology office, on 12 June 2017, 
much improved, and his weight had come down from a peak of $327 \mathrm{lb}$ to $293 \mathrm{lb}$, serum creatinine was down to $1.05 \mathrm{mg} / \mathrm{dL}$ and he was requiring more potassium chloride supplements, on the same dose of Furosemide ( $40 \mathrm{mg}$ twice daily) and Metolazone ( $2.5 \mathrm{mg}$ daily), together with Spironolactone that was reintroduced by his Internist sometime after discharge, at a lower dose of $12.5 \mathrm{mg}$ daily.

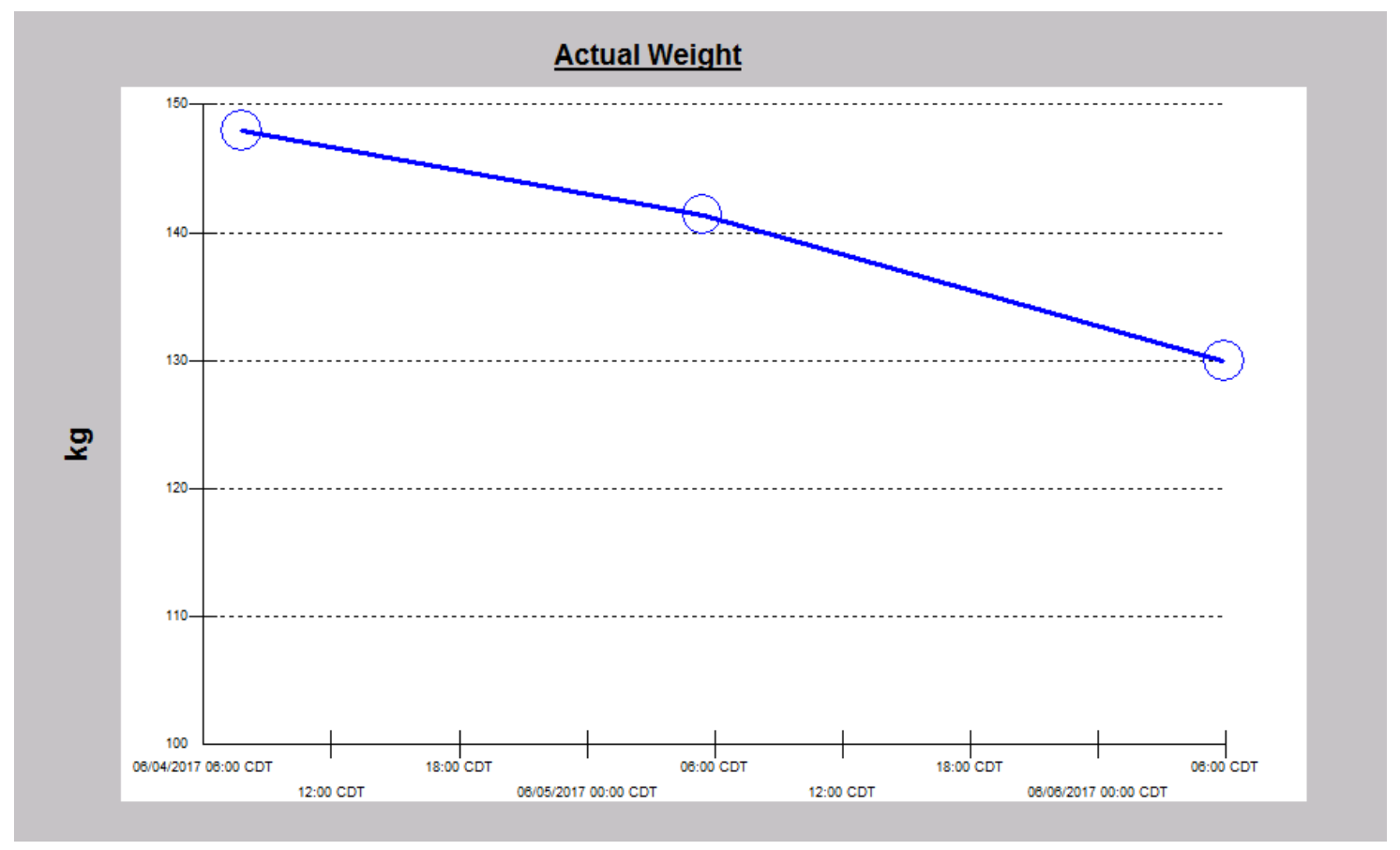

Figure 11. Weight reduction following intravenous decongestive diuresis in Case 3.

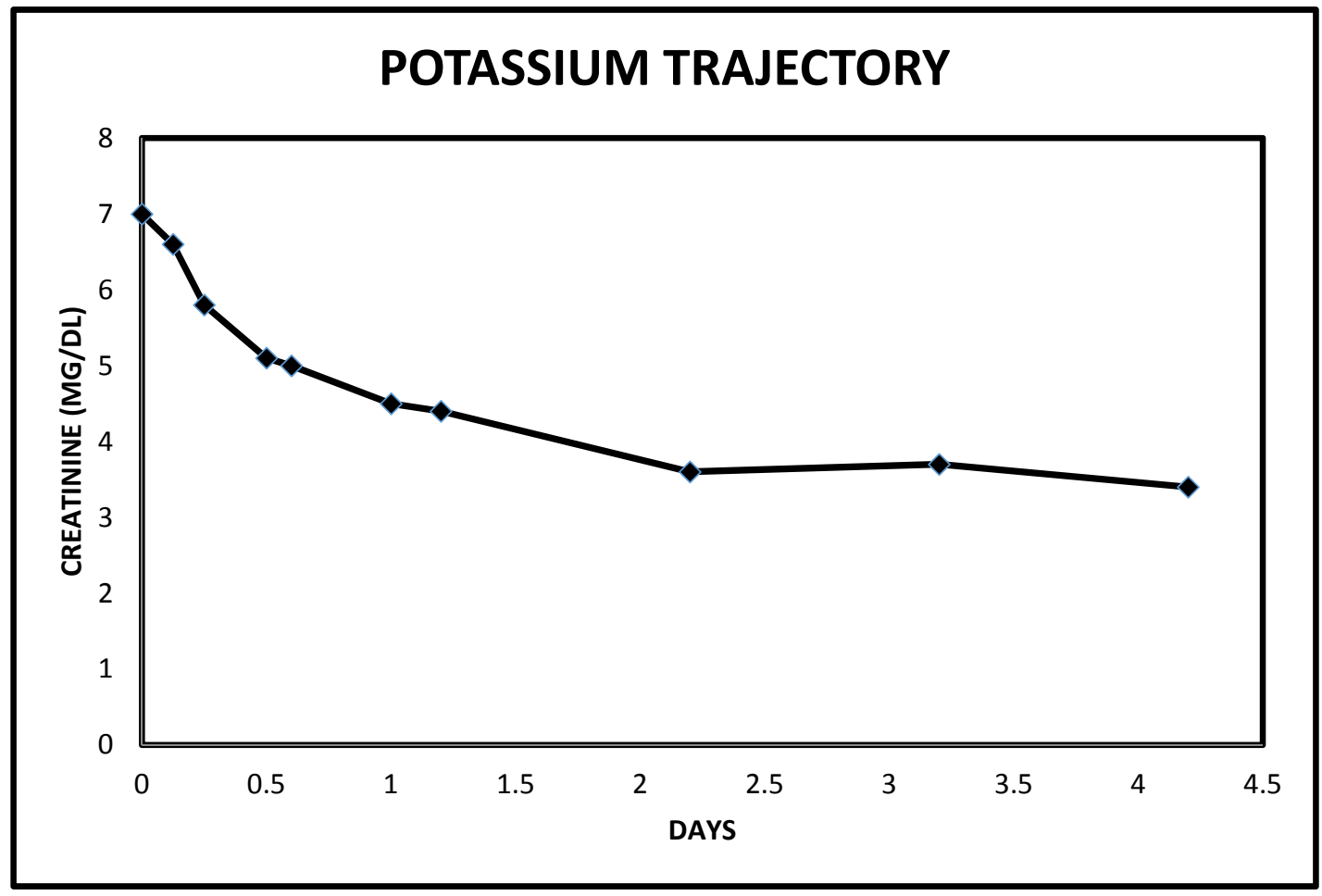

Figure 12. Normalized serum potassium from hyperkalemic levels following intravenous decongestive diuresis in Case 3. 


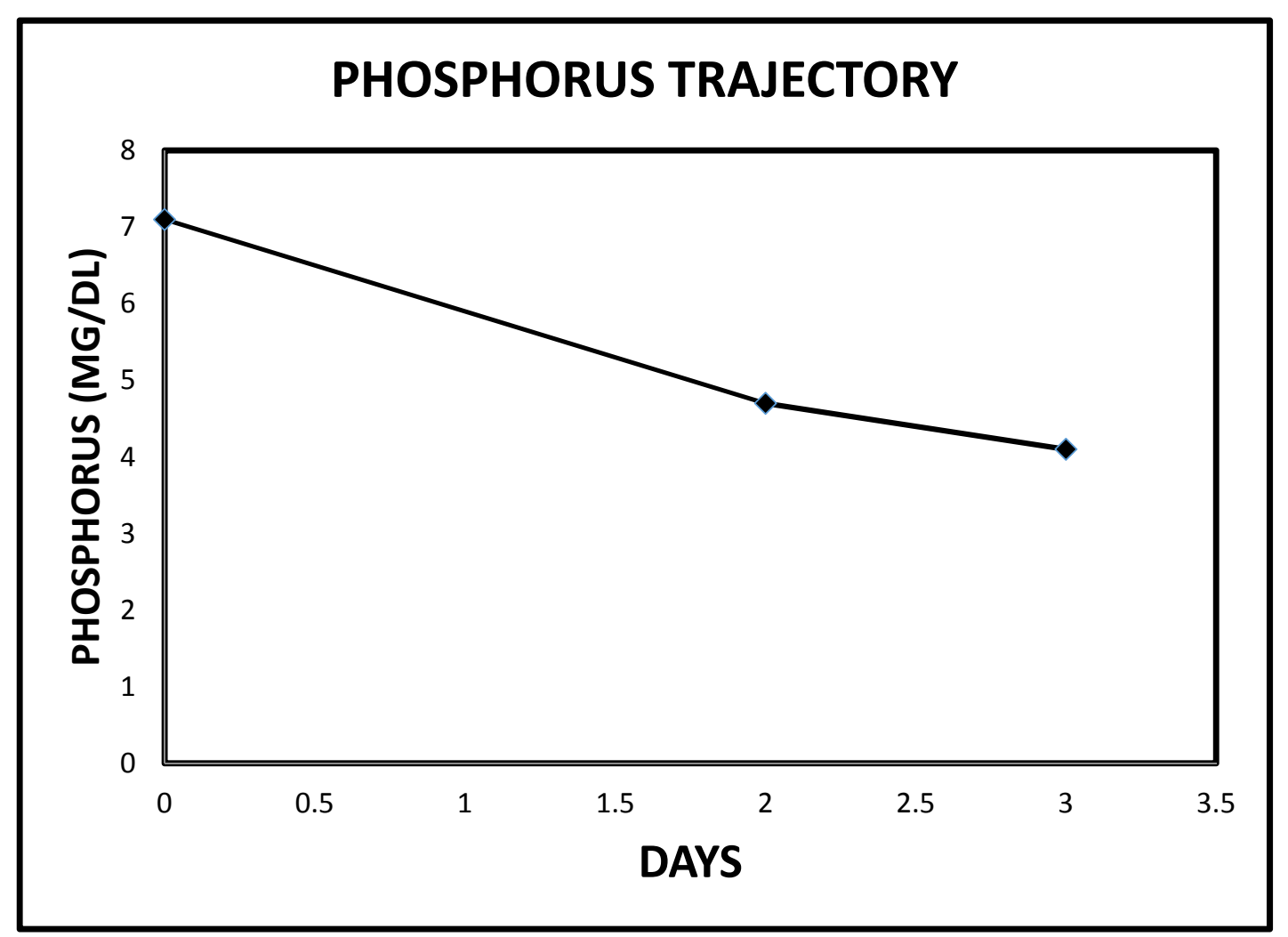

Figure 13. Normalized serum phosphorus from previously hyperphosphatemic levels following intravenous decongestive diuresis in Case 3.

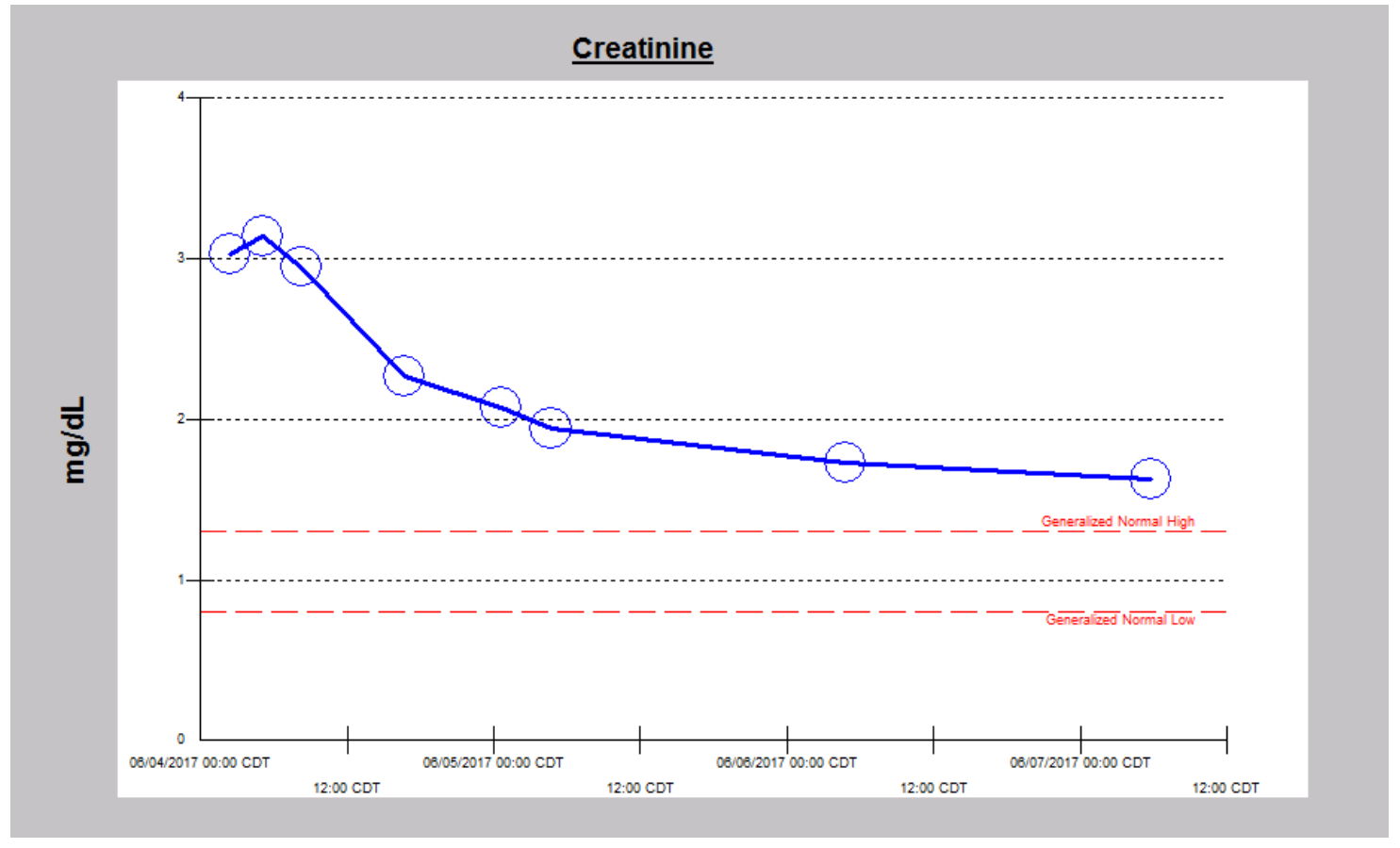

Figure 14. Falling serum creatinine in Case 3 following intravenous decongestive diuresis. 


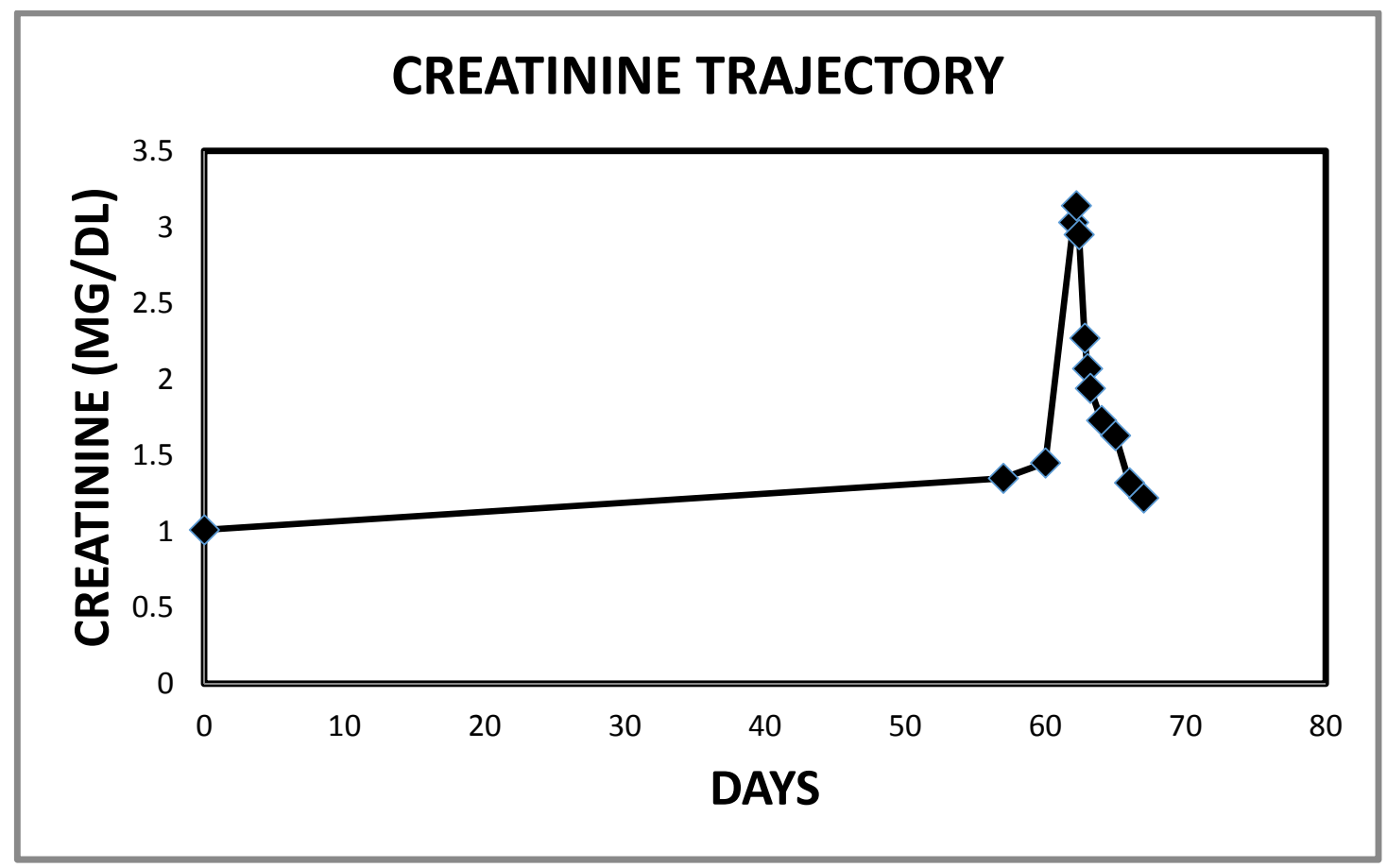

Figure 15. Serum creatinine trajectory in Case 3 leading to and following the use of intravenous decongestive diuresis.

\section{Conclusions}

We have demonstrated very impressive degrees of diuresis in three consecutive patients with symptomatic heart failure, associated worsening renal failure consistent with cardiorenal syndrome, following the utilization of the combination of continuous intravenous Furosemide infusion with intravenous Chlorothiazide given every 8-12 h. Symptomatic heart failure relief with loss of edema and anasarca fluid, weight loss, improvement in dyspnea and orthopnea, as well as simultaneous improvement in renal function was achieved in all three patients in our series. This was true even in patient 3 , where we demonstrated excellent diuretic response, achieving nearly $10 \mathrm{~L}$ of urine in the first twenty-four hours, even in the face of acute kidney injury secondary to contrast nephropathy. This degree of "renal ultrafiltration" far exceeded the mechanical ultrafiltration targets reported in the cardiorenal literature using mechanical dialysis machines [9]; this represents further evidence to attest to the potency of the potential synergy of the simultaneous, concurrent and sequential administration of these two classes of diuretics [10].

In a pooled analysis of 208 patients from the DOSE-AHF, ROSE-AHF, and CARRESS-HF trials, the main finding was that intensifying medical therapies with parenteral diuretics while targeting a 3-5 L/d urine output utilizing intravenous Furosemide with oral Metolazone was associated with a greater amount of weight loss and a higher net fluid loss than standard diuretic therapy with intravenous Furosemide alone without any further worsening of renal function. The group that received intensified diuretic therapy had more weight change $(-3.4 \pm 5.2 \mathrm{lb})$ and more net fluid loss $(1.705 \pm 1.417 \mathrm{~L})$ after $24 \mathrm{~h}$ than the standard diuretic therapy group $(-0.8 \pm 3.4 \mathrm{lb}$ and $0.892 \pm 1.395$ $\mathrm{L}$, respectively; $P<0.001$ for both) with a slight improvement in renal function (creatinine change $-0.1 \pm 0.3$ vs. $0.0 \pm 0.3 \mathrm{mg} / \mathrm{dL}$, respectively; $P=0.03$ ) [11]. The addition of thiazide-type diuretics should be considered when a progressive decrease in loop diuretic efficacy is observed with prolonged use (i.e., the braking phenomenon). Furthermore, thiazide-type diuretics are a useful addition in patients with low GFR to maximally boost fractional sodium excretion when nephron perfusion is poor $[10,12]$. 
Finally, we would wish to emphasize our thrilling observation that all three patients had demonstrated recently rising Pro B Nat Peptide levels prior to each presentation (Table 1, Figures 16-19). As a result of these observations, we have proposed a hypothesis that rapidly rising Pro B Nat Peptide levels in patients presenting a priori with cardiorenal syndrome should be seen as a sign of rapidly increasing right atrial pressure and as a result, the subsequent worsening congestive renal failure secondary to renal venous hypertension and therefore is a predictor of positive response to aggressive decongestive diuresis. Moreover, the often more than logarithmic escalations of Pro B Naturetic Peptide level that were observed within short periods of time prior to presentation in our three patients, we posit, is further confirmation of the very heightened central venous pressures operational in these patients on admission that would have clearly translated to exaggerated renal venous hypertension leading to "congestive renal failure" as designated by Ross in 2012 [1]. Of note, among hemodialysis patients, high Pro B Nat Peptide levels have been associated with mortality and generally is known to trend with volume overload [13-16]. The association of accelerated Pro B Nat Peptide levels with renal and/or mortality outcomes in cardiorenal syndrome not on hemodialysis are unknown. Specific targeted trials are warranted.

Furthermore, the observation of worsening pulmonary hypertension as demonstrated in patient 3 is further testament of the validity of renal venous hypertension in the precipitation and potentiation of renal failure with cardiorenal failure and could also serve as another measurable diagnostic index in this paradigm of care. We would acknowledge that pulmonary hypertension was not evident in patient 1 although she exhibited bi-atrial enlargement. Patient 3 did not have an echocardiogram during the index admission, whereas patient 2 exhibited severe right atrial enlargement.

Table 1. Changes in BNP levels in the three patients at presentation versus the penultimate BNP value.

\begin{tabular}{ccccc}
\hline Patient & $\begin{array}{c}\text { BNP Level at } \\
\text { Presentation }\end{array}$ & $\begin{array}{c}\text { Penultimate BNP } \\
\text { Level }\end{array}$ & Reference Range & $\begin{array}{c}\text { Interval between BNP } \\
\text { Tests (Days) }\end{array}$ \\
\hline 1 & 4907 & 581 & $<450$ PG/ML & 21 \\
2 & 38,547 & 21,557 & $<450$ PG/ML & 63 \\
3 & 5503 & 1426 & $<125$ PG/ML & 16 \\
\hline
\end{tabular}

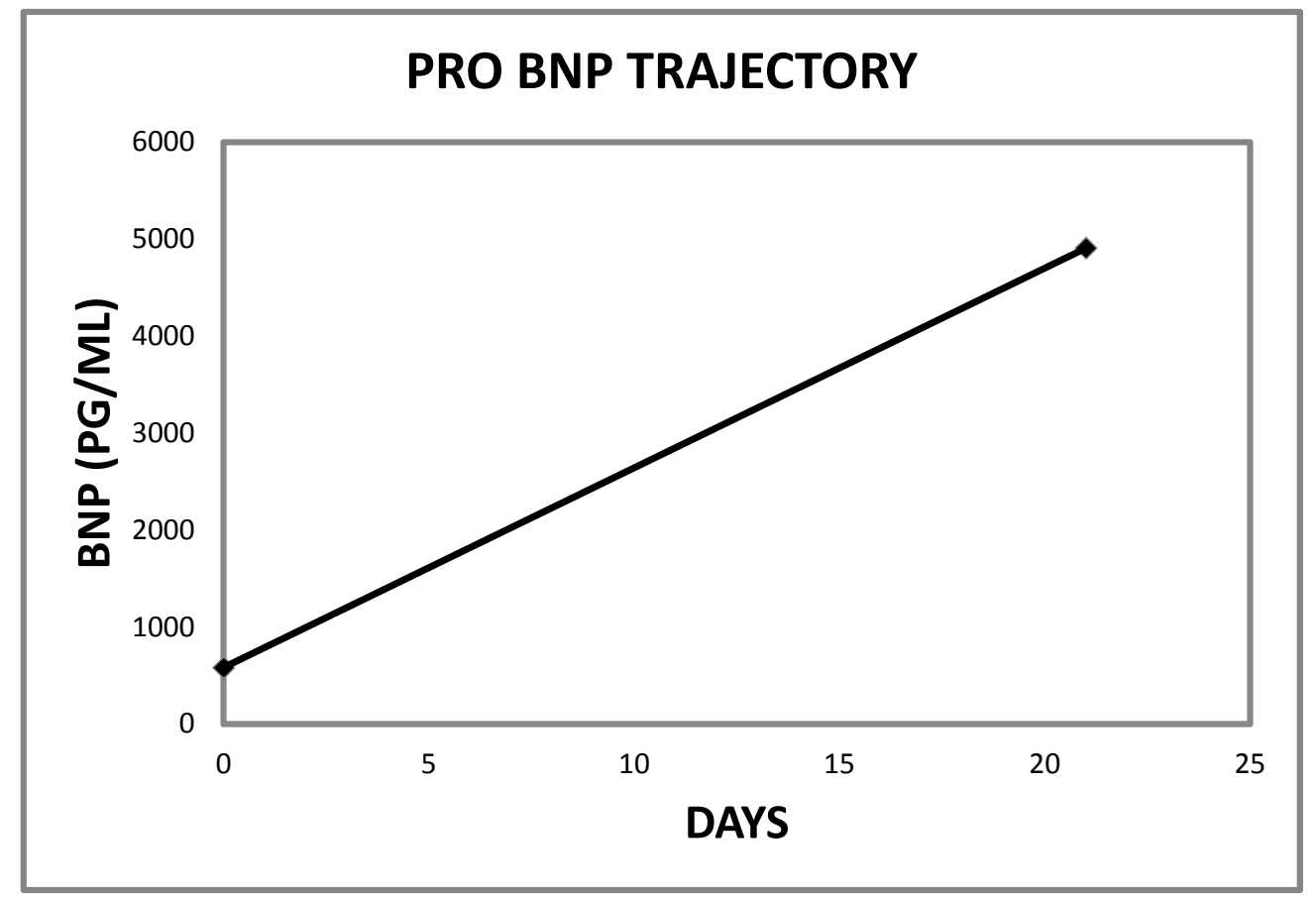

Figure 16. Pro B Nat Pep trajectory in Case 1 immediately preceding the index admission (Reference range for Pro B Nat Pep $\leq 450 \mathrm{pg} / \mathrm{mL}$ ). 


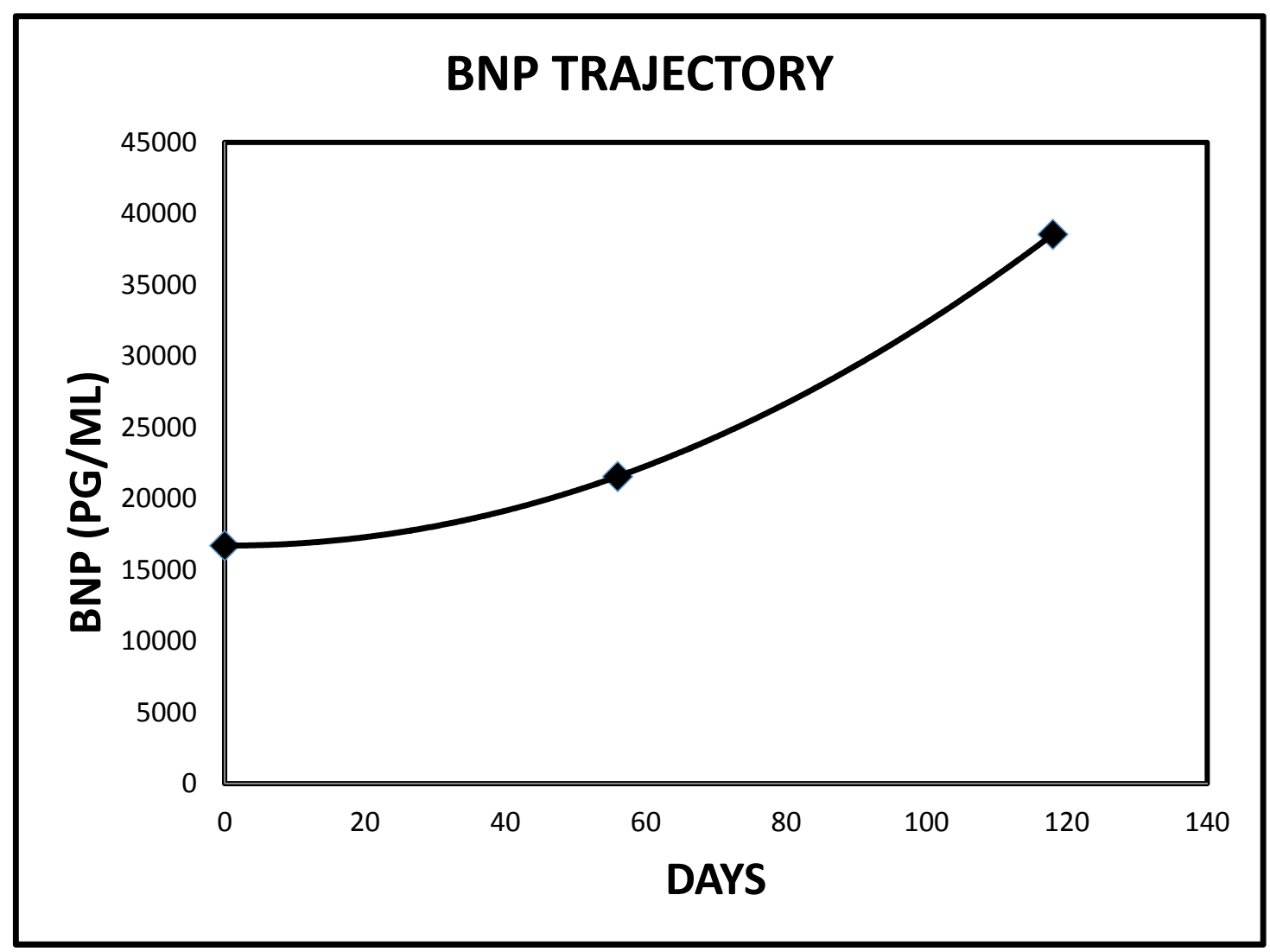

Figure 17. Pro B Nat Pep trajectory in Case 2 immediately preceding the index admission (Reference range for Pro B Nat Pep $\leq 450 \mathrm{pg} / \mathrm{mL}$ ).

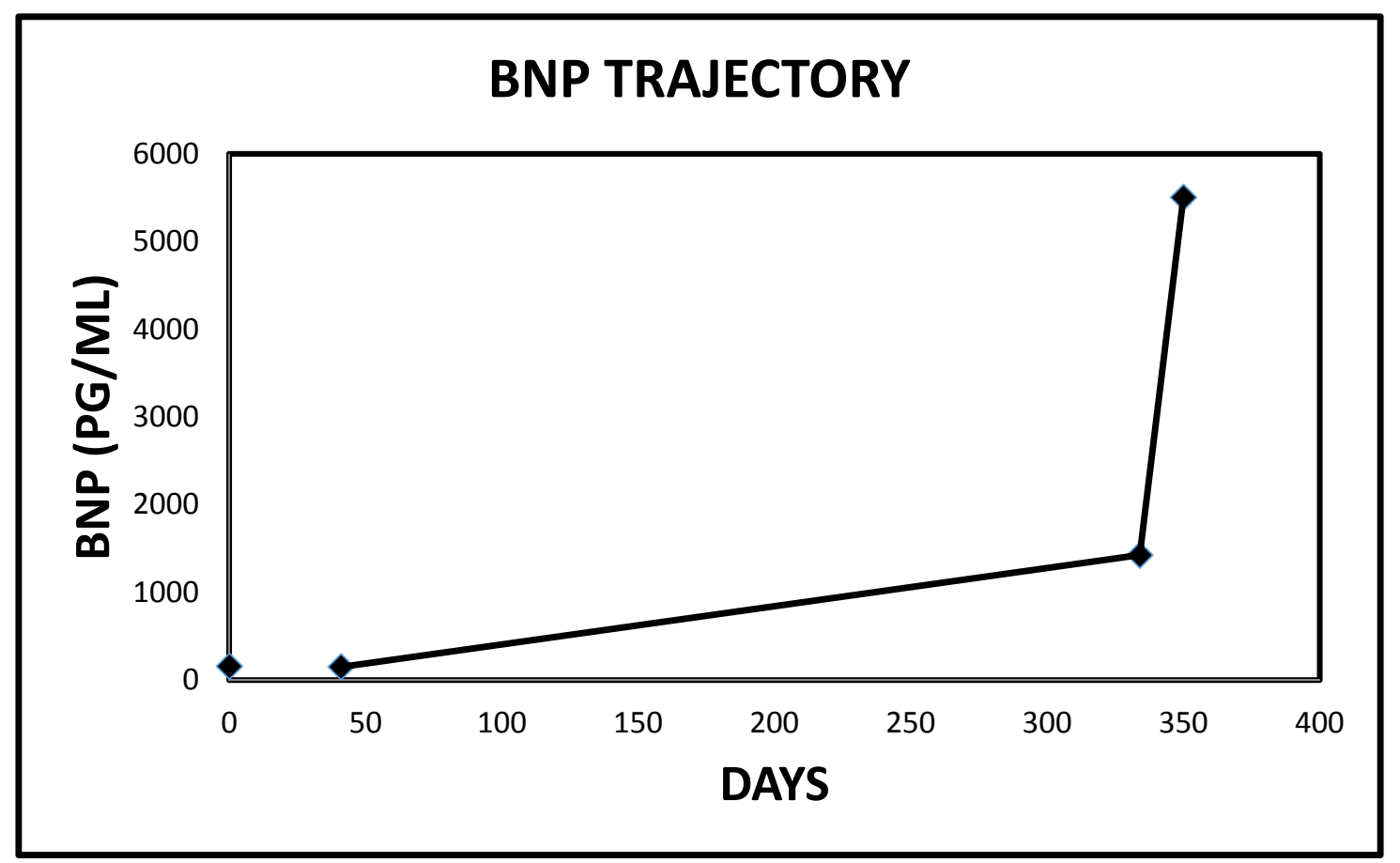

Figure 18. Pro B Nat Pep trajectory in Case 3 immediately preceding the index admission (Reference range for Pro B Nat Pep $\leq 125 \mathrm{pg} / \mathrm{mL}$ ). 


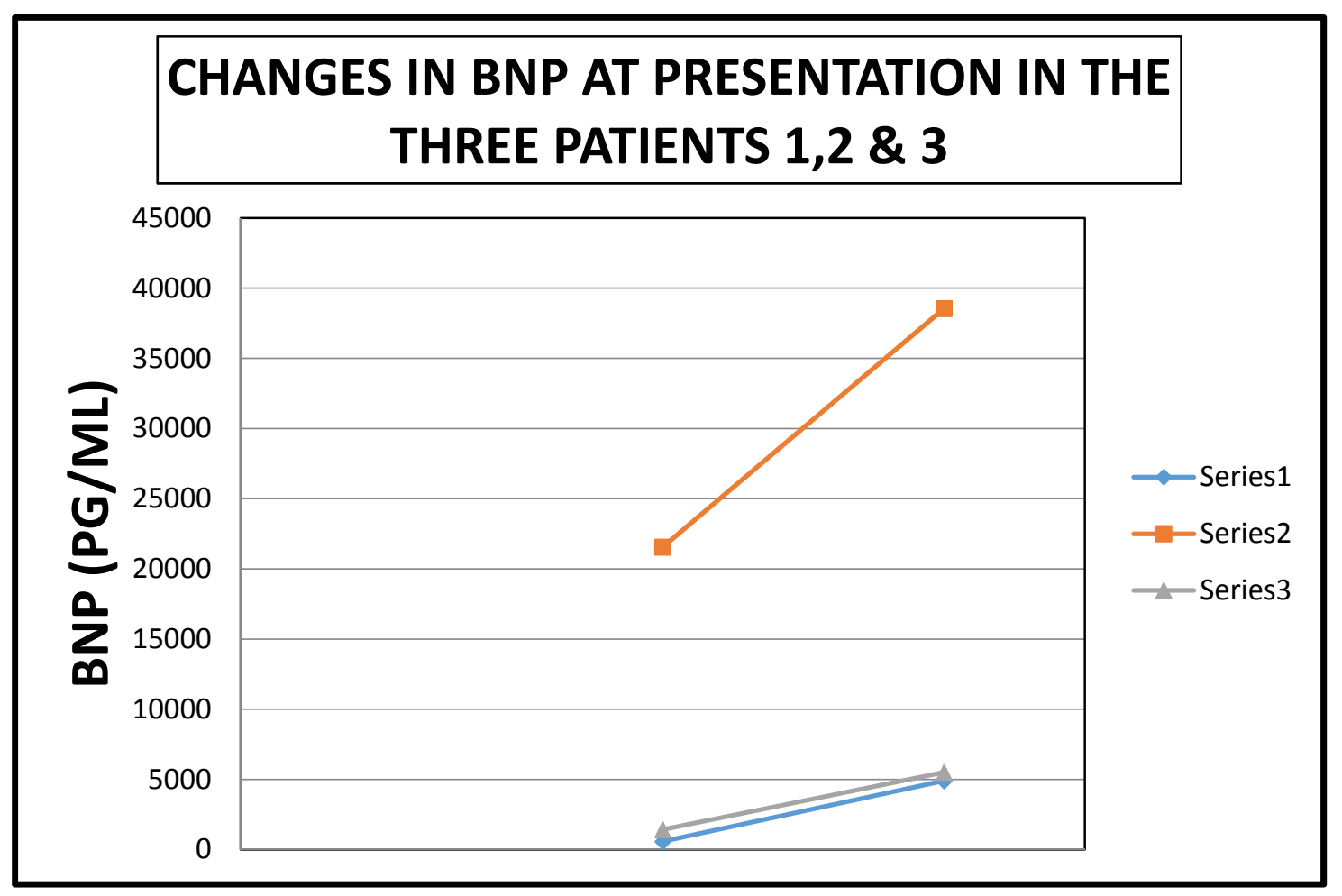

Figure 19. Composite figure showing the acutely rising BNP levels in the three patients at presentation.

\subsection{The Natriuretric Peptides, Heart Failure, Renal Dysfunction and Cardiovascular Disease}

The three known natriuretic peptides are atrial natriuretic peptide (ANP), brain natriuretic peptide (BNP), and C-type natriuretic peptide (CNP) and they contribute to the regulation of cardiovascular homeostasis through diuretic, natriuretic, and vasodilatory properties. Among them, ANP has received particular attention because of its effects on blood pressure regulation and cardiac function. Recently, ANP has also received attention as being a possible cardiovascular risk factor, particularly in the context of hypertension, stroke, obesity, and metabolic syndrome [17]. Furthermore, several reports have correlated elevated BNP biomarker levels with diuretic resistance, hypotension, hyponatremia, longer length of stay, greater inotrope use, and substantially worse survival in patients with renal dysfunction and heart failure, consistent with cardio-renal syndrome [18]. More recently experimental evidence using BNP-deletion has lent stronger impetus to the role of BNP (its absence) in the pathogenesis of hypertension [19]. Finally, the question of renal hyporesponsiveness to high BNP levels and cardiorenal outcomes has been investigated. Egom et al. have observed that several mechanisms have been proposed to explain renal hyporesponsiveness in heart failure, including, but not limited to, decreased renal BNP availability, down-regulation of natriuretic peptide receptors, and altered BNP intracellular signal transduction pathways. Thus, a better understanding of renal hyporesponsiveness in failure is required to devise strategies to develop novel agents and technologies that directly restore renal BNP efficiency. It is hoped that development of these new therapeutic approaches will serve to limit sodium retention in patients with heart failure, which may ultimately delay the progression to overt heart failure [20]. However, these topics, albeit exciting and intriguing, remain beyond the scope of our current manuscript.

\subsection{Diuretic Resistance in Cardiorenal Syndrome}

Verbrugge et al. in a 2016 review had acknowledged that diuretic resistance in acute heart failure has emerged as a powerful predictor of adverse outcome, which is often independent of underlying glomerular filtration rate [12]. One of the conclusions was that the addition of thiazide-type 
diuretics should be considered when a progressive decrease in loop diuretic efficacy is observed with prolonged use (i.e., the braking phenomenon). We posit that our three case presentations support the clinical reality of this braking phenomenon [10]. Moreover, according to Verbrugge et al., in a 2015 prospective, single-center cohort study, consecutive patients with decompensated heart failure $(n=54)$ and left ventricular ejection fraction $45 \%$ received protocol-driven diuretic therapy until complete disappearance of congestion signs. Urine was collected during three consecutive 24-h intervals. Natriuretic response was defined as absolute natriuresis $(\mathrm{mmol})$ per $\mathrm{mg}$ of intravenous bumetanide administered [12]. Natriuresis was $146 \mathrm{mmol}(76-206 \mathrm{mmol}), 74 \mathrm{mmol}(37-167 \mathrm{mmol})$ and $74 \mathrm{mmol}$ (53-134 mmol) per mg intravenous bumetanide administered during the first, second and third 24-h interval, respectively [12]. Diastolic blood pressure (beta $=23.048 \pm 10.788 ; p$-value $=0.036$ ), plasma aldosterone (beta $=-25.722 \pm 11.560 ; p$-value $=0.029$ ), and combination therapy with acetazolamide (beta $=103.241 \pm 40.962 ; p$-value $=0.014$ ) were independent predictors of the natriuretic response [12]. Patients with a stronger natriuretic response demonstrated more pronounced decreases in plasma NT-proBNP levels ( $p$-value $=0.025)$ [12]. This would support our hypothesis that acutely rising $\mathrm{BNP}$ levels at presentation with diuretic resistance may predict better decongestive therapy responses. More studies are warranted.

Finally, it is our submission that in selected patients presenting with acute decompensating heart failure concurrent with worsening renal failure and other related electrolyte and metabolic derangements, the judicious use of simultaneously administered continuous Furosemide infusion and intravenous Chlorothiazide could result in very significant cardiorenal salvage. It would appear that escalating levels of Pro B Naturetic Peptide may represent a good prognosticator for a good response to this form of decongestive diuresis. There is evidence in the literature that cardiorenal patients with a stronger natriuretic response demonstrated more pronounced decreases in plasma NT-proBNP levels $(p$-value $=0.025)$ [12]. This is yet another set of evidence supporting the significant role of congestive renal failure in our understanding and proper management of patients with cardiorenal syndrome $[1-7,21]$. Such therapeutic maneuvers would prove invaluable to practitioners in resource-poor settings without access to mechanical ultrafiltration with dialysis or similar equipment.

Acknowledgments: This work is dedicated to Nnamdi Agbasi, my brother-in-law, who passed away at the Nnamdi Azikiwe University Teaching Hospital, Nnewi, Anambra State, Nigeria, after a brief illness earlier in 2017. May his soul rest in peace. Amen.

Author Contributions: Macaulay Amechi Chukwukadibia Onuigbo MD MSc FWACP FASN MBA-Conception, design, acquisition of data, data analysis, interpretation of data, literature review, drafting the article and final approval of manuscript. Nneoma Agbasi RMN MSc PGDip-Critical revising for important intellectual content, design, and final approval of manuscript. Mohan Sengodan MD-Acquisition of data, data analysis and final approval of manuscript. Karen Flores Rosario MS IV-Acquisition of data, data analysis, literature review and final approval of manuscript.

Conflicts of Interest: The authors declare no conflict of interest.

\section{References}

1. Ross, E.A. Congestive renal failure: The pathophysiology and treatment of renal venous hypertension. J. Card. Fail. 2012, 18, 930-938. [CrossRef] [PubMed]

2. Heywood, J.T.; Fonarow, G.C.; Costanzo, M.R.; Mathur, V.S.; Wigneswaran, J.R.; Wynne, J. ADHERE Scientific Advisory Committee and Investigators. High prevalence of renal dysfunction and its impact on outcome in 118,465 patients hospitalized with acute decompensated heart failure: A report from the ADHERE database. J. Card. Fail. 2007, 13, 422-430. [CrossRef] [PubMed]

3. Nohria, A.; Hasselblad, V.; Stebbins, A.; Pauly, D.F.; Fonarow, G.C.; Shah, M.; Yancy, C.W.; Califf, R.M.; Stevenson, L.W.; Hill, J.A. Cardiorenal interactions: Insights from the ESCAPE trial. J. Am. Coll. Cardiol. 2008, 51, 1268-1274. [CrossRef] [PubMed]

4. Damman, K.; van Deursen, V.M.; Navis, G.; Voors, A.A.; van Veldhuisen, D.J.; Hillege, H.L. Increased central venous pressure is associated with impaired renal function and mortality in a broad spectrum of patients with cardiovascular disease. J. Am. Coll. Cardiol. 2009, 53, 582-588. [CrossRef] [PubMed] 
5. Damman, K.; Voors, A.A.; Hillege, H.L.; Navis, G.; Lechat, P.; van Veldhuisen, D.J.; Dargie, H.J. CIBIS-2 Investigators and Committees. Congestion in chronic systolic heart failure is related to renal dysfunction and increased mortality. Eur. J. Heart Fail. 2010, 12, 974-982. [CrossRef] [PubMed]

6. Guglin, M.; Rivero, A.; Matar, F.; Garcia, M. Renal dysfunction in heart failure is due to congestion but not low output. Clin. Cardiol. 2011, 34, 113-136. [CrossRef] [PubMed]

7. Maeder, M.T.; Holst, D.P.; Kaye, D.M. Tricuspid regurgitation contributes to renal dysfunction in patients with heart failure. J. Card. Fail. 2008, 14, 824-830. [CrossRef] [PubMed]

8. Rafique, Z.; Weir, M.R.; Onuigbo, M.; Pitt, B.; Lafayette, R.; Butler, J.; Lopes, M.; Farnum, C.; Peacock, W.F. Expert Panel Recommendations for the Identification and Management of Hyperkalemia and Role of Patiromer in Patients with Chronic Kidney Disease and Heart Failure. J. Manag. Care Spec Pharm. 2017, 23, S10-S19. [CrossRef] [PubMed]

9. Rossi, G.P.; Calò, L.A.; Maiolino, G.; Zoccali, C. Ultrafiltration for the treatment of congestion: A window into the lung for a better caress to the heart. Nephrol. Dial. Transplant. 2014, 29, 1335-1341. [CrossRef] [PubMed]

10. Verbrugge, F.H.; Mullens, W.; Tang, W.H. Management of Cardio-Renal Syndrome and Diuretic Resistance. Curr. Treat. Opt. Cardiovasc. Med. 2016, 18, 11. [CrossRef] [PubMed]

11. Grodin, J.L.; Stevens, S.R.; de Las Fuentes, L.; Kiernan, M.; Birati, E.Y.; Gupta, D.; Bart, B.A.; Felker, G.M.; Chen, H.H.; Butler, J.; et al. Intensification of Medication Therapy for Cardiorenal Syndrome in Acute Decompensated Heart Failure. J. Card. Fail. 2016, 22, 26-32. [CrossRef] [PubMed]

12. Verbrugge, F.H.; Dupont, M.; Bertrand, P.B.; Nijst, P.; Penders, J.; Dens, J.; Werhaert, D.; Vandervoort, P.; Wilson Tang, W.H.; Mullens, W. Determinants and impact of the natriuretic response to diuretic therapy in heart failure with reduced ejection fraction and volume overload. Acta Cardiol. 2015, 70, 265-273. [CrossRef] [PubMed]

13. Corboy, J.C.; Walker, R.J.; Simmonds, M.B.; Wilkins, G.T.; Richards, A.M.; Espiner, E.A. Plasma natriuretic peptides and cardiac volume during acute changes in intravascular volume in haemodialysis patients. Clin. Sci. 1994, 87, 679-684. [CrossRef] [PubMed]

14. Van de Pol, A.C.; Frenken, L.A.; Moret, K.; Baumgarten, R.; van der Sande, F.M.; Beerenhout, C.M.; Kooman, J.P.; Leunissen, K.M. An evaluation of blood volume changes during ultrafiltration pulses and natriuretic peptides in the assessment of dry weight in hemodialysis patients. Hemodial. Int. 2007, 11, 51-61. [CrossRef] [PubMed]

15. Tapolyai, M.; Uysal, A.; Maeweathers, G.; Bahta, E.; Dossabhoy, N.R. B-type natriuretic peptide-directed ultrafiltration improves care in acutely hospitalized dialysis patients. Congest. Heart Fail. 2009, 15, 131-135. [CrossRef] [PubMed]

16. Ishigami, J.; Iimori, S.; Kuwahara, M.; Sasaki, S.; Tsukamoto, Y. Diagnostic value of B-type natriuretic peptide for estimating left atrial size and its usefulness for predicting all-cause mortality and cardiovascular events among chronic haemodialysis patients. Nephrology 2014, 19, 777-783. [CrossRef] [PubMed]

17. Rubattu, S.; Sciarretta, S.; Valenti, V.; Stanzione, R.; Volpe, M. Natriuretic peptides: An update on bioactivity, potential therapeutic use, and implication in cardiovascular diseases. Am. J. Hypertens. 2008, 21, 733-741. [CrossRef] [PubMed]

18. Testani, J.M.; Damman, K.; Brisco, M.A.; Chen, S.; Laur, O. A combined-biomarker approach to clinical phenotyping renal dysfunction in heart failure. J. Card. Fail. 2014, 20, 912-919. [CrossRef] [PubMed]

19. Holditch, S.J.; Schreiber, C.A.; Nini, R.; Tonne, J.M.; Peng, K.W.; Geurts, A.; Jacob, H.J.; Burnett, J.C.; Cataliotti, A.; Ikeda, Y. B-Type Natriuretic Peptide Deletion Leads to Progressive Hypertension, Associated Organ Damage, and Reduced Survival: Novel Model for Human Hypertension. Hypertension 2015, 66, 199-210. [CrossRef] [PubMed]

20. Egom, E.E.; Feridooni, T.; Hotchkiss, A.; Kruzliak, P.; Pasumarthi, K.B. Mechanisms of renal hyporesponsiveness to BNP in heart failure. Can. J. Physiol. Pharmacol. 2015, 93, 399-403. [CrossRef] [PubMed]

21. Onuigbo, M.A. RAAS inhibition and cardiorenal syndrome. Curr. Hypertens. Rev. 2014, 10, $107-111$. [CrossRef] [PubMed]

(C) 2017 by the authors. Licensee MDPI, Basel, Switzerland. This article is an open access article distributed under the terms and conditions of the Creative Commons Attribution (CC BY) license (http://creativecommons.org/licenses/by/4.0/). 